\title{
A New Unified Solution for Circular Tunnel Based on a Four-Stage Constitutive Model considering the Intermediate Principal Stress
}

\author{
Liang Chen $\mathbb{D}^{1,2}$, Xianbiao Mao $\mathbb{D}^{1,}{ }^{1,2}$ Yanlong Chen $\mathbb{D}^{1,},{ }^{1,2}$ Ming Li, ${ }^{1,2}$ Yang Hao $\mathbb{D}^{1,2}$ \\ and Ding Liu $\mathbb{1}^{1,2}$ \\ ${ }^{1}$ State Key Laboratory for Geomechanics and Deep Underground Engineering, China University of Mining \& Technology, \\ Xuzhou 221116, China \\ ${ }^{2}$ School of Mechanics and Civil Engineering, China University of Mining \& Technology, Xuzhou 221116, China
}

Correspondence should be addressed to Xianbiao Mao; xbmaocumt@163.com

Received 28 December 2017; Revised 31 January 2018; Accepted 22 February 2018; Published 19 April 2018

Academic Editor: Rihong Cao

Copyright (c) 2018 Liang Chen et al. This is an open access article distributed under the Creative Commons Attribution License, which permits unrestricted use, distribution, and reproduction in any medium, provided the original work is properly cited.

Based on the triaxial test, the elasto-perfectly plastic strain-softening damage model (EPSDM) is proposed as a new four-stage constitutive model. Compared with traditional models, such as the elasto-brittle-plastic model (EBM), elasto-strain-softening model (ESM), elasto-perfectly plastic model (EPM), and elasto-peak plastic-brittle plastic model (EPBM), this model incorporates both the plastic bearing capacity and strain-softening characteristics of rock mass. Moreover, a new closed-form solution of the circular tunnel is presented for the stress and displacement distribution, and a plastic shear strain increment is introduced to define the critical condition where the strain-softening zone begins to occur. The new analysis solution obtained in this paper is a series of results rather than one specific solution; hence, it is suitable for a wide range of rock masses and engineering structures. The numerical simulation has been used to verify the correctness of the EPSDM. The parametric studies are also conducted to investigate the effects of supporting resistance, residual cohesion, dilation angle, strain-softening coefficient, plastic shear strain increment, and yield parameter on the result. It is shown that when the supporting resistance is fully released, both the post-peak failure radii and surface displacement could be summarized as EBM $>$ EPBM $>$ ESM $>$ EPSDM $>$ EPM; the dilation angle in the damage zone had the highest influence on the surface displacement, whereas the dilation angle in the perfectly plastic zone had the lowest influence; the strainsoftening coefficient had the most significant effect on the damage zone radii; the EPSDM is recommended as the optimum model for support design and stability evaluation of the circular tunnel excavated in the perfectly plastic strain-softening rock mass.

\section{Introduction}

Although the plane strain of circular holes is a relatively simple problem, it can provide effective theoretical basis for the support parameter design and stability evaluation of surrounding rock in underground engineering. Therefore, it has been widely applied in the tunnel, coal mine shaft construction, oil extraction, coal gas penetration, and other projects.

In the early stage, the elastoplastic analysis of the circular tunnel was first proposed by Fenner and then corrected by Kastner. However, both of them regarded the rock mass as a perfectly elastoplastic material. In recent years, a series of studies have been carried out by using the linear MohrCoulomb (M-C) criterion, nonlinear Hoek-Brown (H-B) criterion, and the generalized Hoek-Brown (GHB) criterion with the associated and nonassociated flow rule. However, the influence of intermediate principal stress on the surrounding rock state was ignored [1-11]. A large number of studies have shown that rock strength is not only related to its own characteristics but also closely related to its stress state [12-14]. In practice, the shallow rock mass is still in the triaxial stress state under the effect of the supporting structure after tunnel excavation. Then, the yield strength of rock mass increased due to the influence of intermediate principal stress, which in turn would affect the stress and deformation of surrounding rock. Therefore, intermediate principal stress is crucial for tunnel design $[15,16]$. The unified strength theory (UST) not only considers the impact of all stress components on material yield failure under different stress states but also is applicable to a variety of 


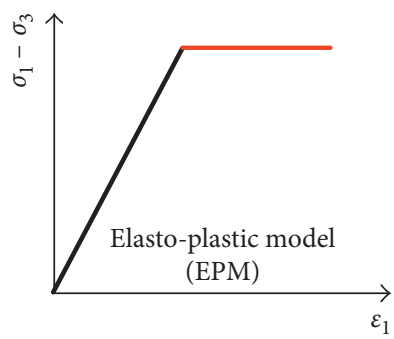

(a)

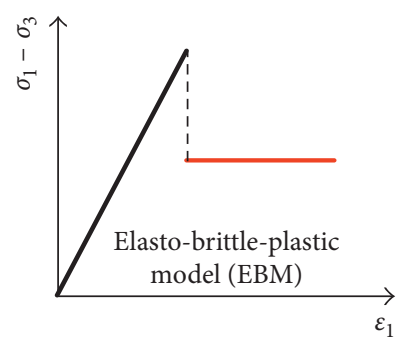

(b)

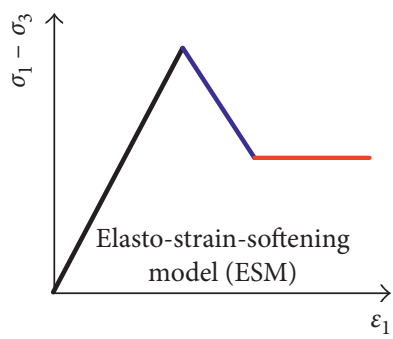

(c)

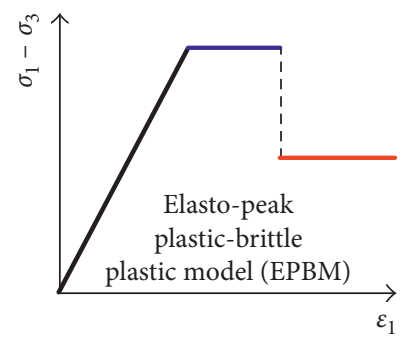

(d)

Figure 1: Previous research model.

material mediums at good accuracy. Thus, it was chosen as the failure criterion of the rock material [17-24].

It is known that the elastoplastic analysis problems of surrounding rock are mainly dependent on the constitutive relations of rock mass. As a natural geological body, the rock material is easily affected by internal fissures, joints, components, and external environment. Therefore, its constitutive relation is extremely complicated. As shown in Figure 1, the elasto-brittle-plastic model (EBM), elasto-strain-softening model (ESM), and elasto-perfectly plastic model (EPM) were usually used to research this problem [1, 4-10, 22, 25-30]. However, based on the geotechnical quality, Hoek and Brown pointed out that the EBM was applied only to the poor-quality rock mass, while EPM and ESM were suitable for the highquality and average-quality rock masses, respectively [31]. Then, Zhang et al. [11] and Jiang et al.'s [32, 33] experiment showed that a plastic bearing zone before brittle failure for the rock material under high confining pressures could exist. Thus, the elasto-peak plastic-brittle plastic model (EPBM) was presented (Figure 1(d)) and applied to the Jinping II hydropower station engineering. Nevertheless, when the confining pressures were $5 \mathrm{MPa}$ and $40 \mathrm{MPa}$ in Zhang's triaxial test, the brittle rock material showed obvious strain-softening characteristics from the peak plastic state to the brittle plastic state. Therefore, it may not be reasonable to simplify the EPBM. As shown in Figure 2, a large number of rock masses firstly showed the strain-softening characteristics after the peak plastic zone and then entered the residual flow stage. Therefore, according to the total stress-strain curve, the elasto-perfectly plastic strain-softening damage model (EPSDM) was proposed in this paper and then applied to the engineering practice. Actually, the EPSDM includes all the features of the EPM, EBM, ESM, and EPBM and can be transformed into the above four models under certain conditions. Hence, it can be regarded as a unified constitutive model.

Based on the triaxial test, the elasto-perfectly plastic strain-softening damage model (EPSDM) is proposed as a new four-stage constitutive model. Then, a new closedform solution of the circular opening is deduced based on UST and EPSDM, and a plastic shear strain increment is introduced to determine the critical condition that the strain-softening zone begins to develop. The correctness of the solution has been verified by making a comparative analysis of Pan's numerical simulation results [23]. Finally, the effect of the parameters is also discussed.

\section{Problem Description}

2.1. The Establishment of EPSDM. Figure 3 shows a circular tunnel being excavated in a unified, continuous, isotropic UST rock mass subjected to a hydrostatic pressure $\left(\sigma_{0}\right)$ at infinity boundary and a supporting resistance $\left(p_{\text {in }}\right)$ at inner radius ( $a)$. As $p_{\text {in }}$ gradually reduces, the rock mass begins to enter the perfectly plastic stage ("AB") when the maximum and the minimum principal stresses satisfy the initial yield conditions. This stage is not an infinite extension whose range should be restricted by some factors. Assuming the plastic shear strain increment of the perfectly plastic zone reaches a certain value, the rock mass will begin to enter the strain-softening stage ("BC") where the rock mass cohesion gradually decreases. Until a residual value is reached, the rock mass starts to enter the damage stage and finally achieves a equilibrium state under the supporting resistance. Meanwhile, the radii of the perfectly plastic zone, strainsoftening zone, and damage zone are denoted as $R_{\mathrm{p}}, R_{\mathrm{s}}$, and $R_{\mathrm{c}}$, respectively.

2.2. Unified Strength Theory (UST). Based on the twin shear yield criterion, the unified strength theory is established by considering the influence of all the stress components and intermediate principal stress on the material yield failure $[19-22,24]$. The UST is a series of yield criteria and failure criteria, which can be adopted for most materials. In geotechnical engineering, the cohesion (c) and the internal friction angle $(\varphi)$ are usually used to represent this yield theory. In general, the compressive stress is positive and the tensile stress is negative. Therefore, the UST yield function can be expressed as follows [24]:

$$
\text { when } \begin{aligned}
\sigma_{2} & \leq\left(\left(\sigma_{1}+\sigma_{3}\right) / 2\right)-\left(\left(\sigma_{1}-\sigma_{3}\right) / 2\right) \sin \varphi, \\
F & =\frac{1-\sin \varphi}{1+\sin \varphi} \sigma_{1}-\frac{b \sigma_{2}+\sigma_{3}}{1+b}=\frac{2 c \cos \varphi}{1+\sin \varphi}
\end{aligned}
$$

When $\sigma_{2} \geq\left(\left(\sigma_{1}+\sigma_{3}\right) / 2\right)-\left(\left(\sigma_{1}-\sigma_{3}\right) / 2\right) \sin \varphi$,

$$
F^{\prime}=\frac{1-\sin \varphi}{(1+b)(1+\sin \varphi)}\left(\sigma_{1}+b \sigma_{2}\right)-\sigma_{3}=\frac{2 c \cos \varphi}{1+\sin \varphi},
$$

where $F$ and $F^{\prime}$ represent the yield function; $\sigma_{1}, \sigma_{2}$, and $\sigma_{3}$ represent the maximum, intermediate, and minimum principal stresses, respectively; $b$ represents the yield parameter related to the intermediate principal stress, which can reflect the effect of the intermediate principal shear 


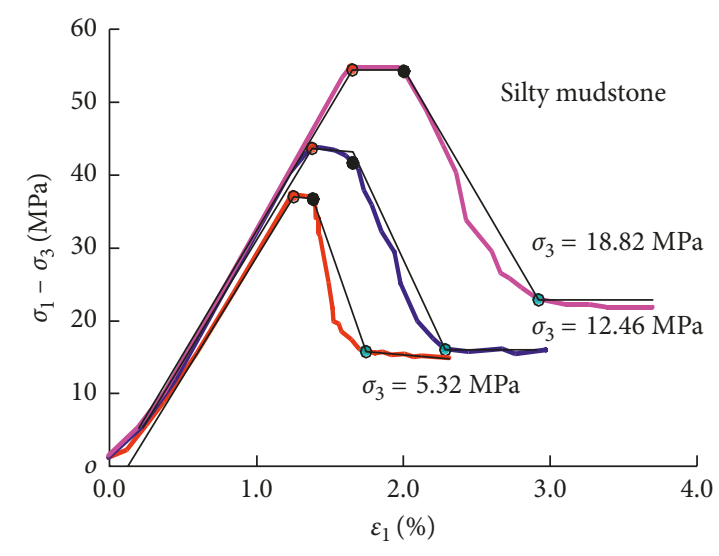

(a)

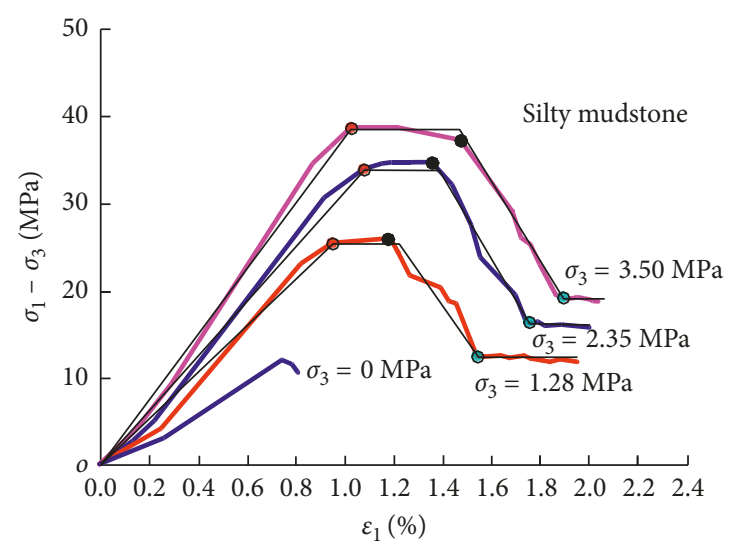

(b)

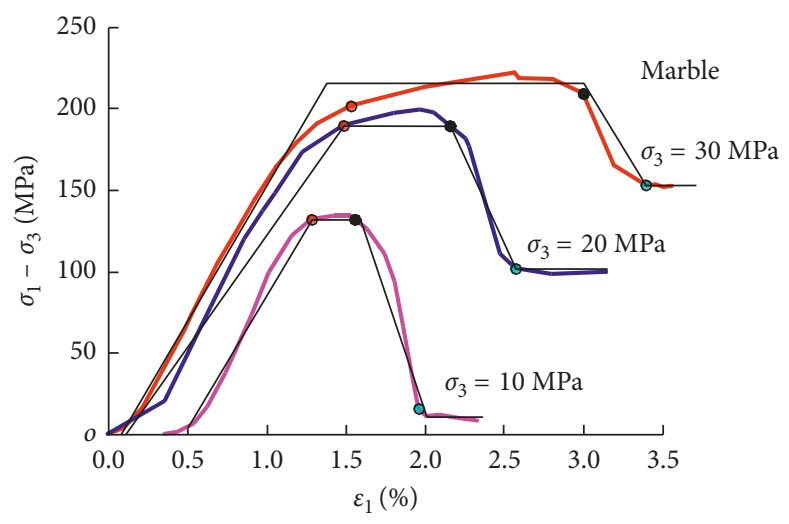

(c)

Figure 2: Total stress-strain curve of rock mass in the local area of China: (a) Yangzhuang coal mine in Henan Province; (b) Wushan area of Chongqing; (c) Ya'an area of Sichuan.

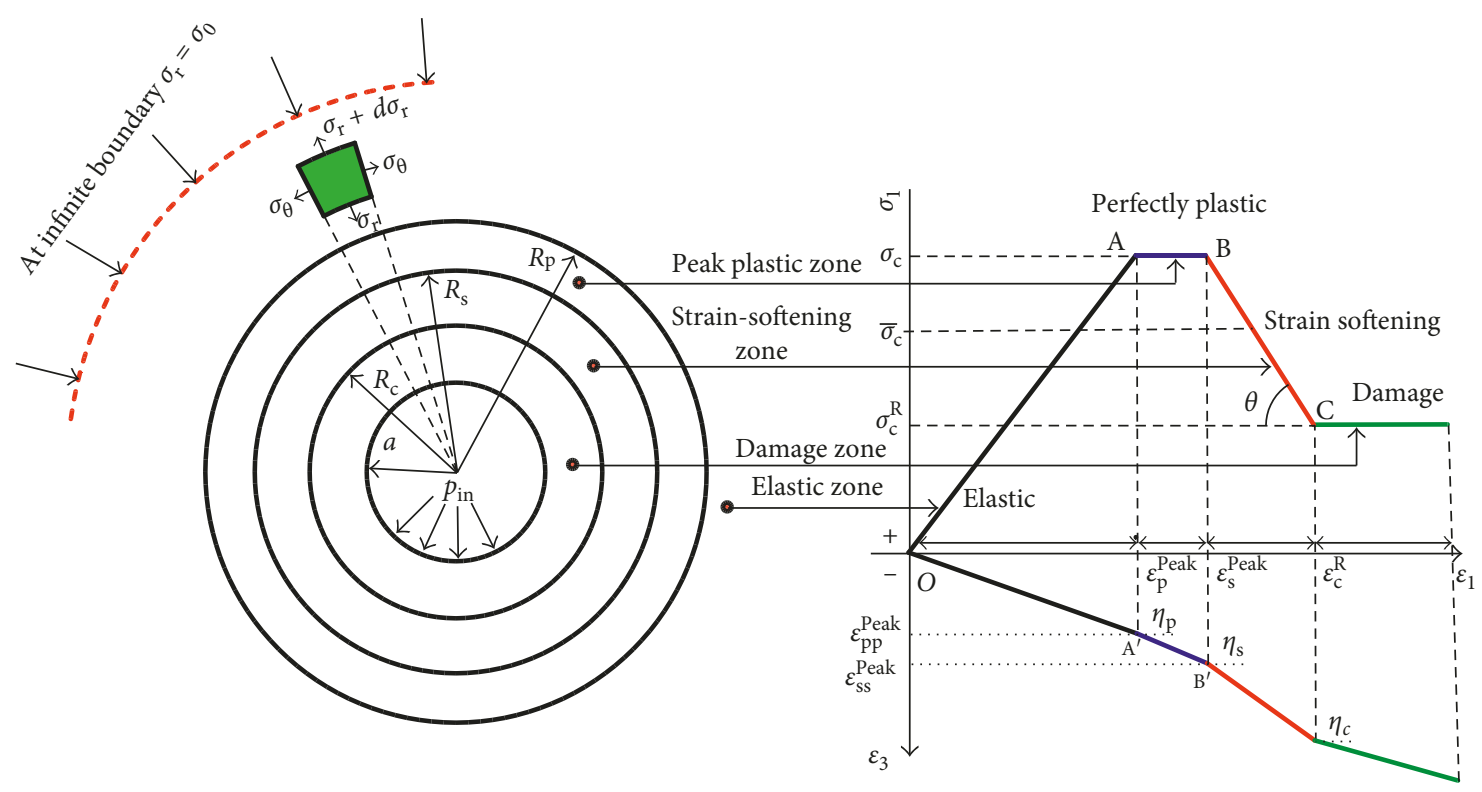

FIGURE 3: EPSDM of the circular tunnel.

stress and the positive stress on the yield failure of the rock material, and $0 \leq b \leq 1$. When $b=0$, UST translates into the $\mathrm{M}-\mathrm{C}$ strength criterion; when $b=1$, UST translates into the general twin shear strength (GTSS) criterion; when $0<b<1$, UST translates into a series of other ordered new strength criteria. 
Under axisymmetric plane strain conditions, the relationship among three principal stresses is generally expressed as the parameter $n[15,22]$ :

$$
\sigma_{2}=\frac{n\left(\sigma_{1}+\sigma_{3}\right)}{2} \text {. }
$$

For rock materials, $n$ generally satisfies $2 v \leq n \leq 1$. When $n \rightarrow 1, \sigma_{2}$ becomes closer to the average of maximum and minimum principal stresses; $v$ is Poisson's ratio. In order to simplify the calculation, we take $n=1 . \sigma_{2} \geq\left(\left(\sigma_{1}+\sigma_{3}\right) / 2\right)-$ $\left(\left(\sigma_{1}-\sigma_{3}\right) / 2\right) \sin \varphi$ can be judged by substituting $\sigma_{2}=\left(\sigma_{1}+\right.$ $\left.\sigma_{3}\right) / 2$ into (1) or (2). Therefore, UST can be rewritten as

$$
\sigma_{1}=N_{\mathrm{p}} \sigma_{3}+\sigma_{\mathrm{c}}
$$

where $N_{\mathrm{p}}=(2+b+(2+3 b) \sin \varphi) /((2+b)(1-\sin \varphi))$ and $\sigma_{\mathrm{c}}=(4(1+b) c \cos \varphi) /((2+b)(1-\sin \varphi))$.

For axisymmetric plane strain problems, when $p_{\text {in }}<\sigma_{0}$, the circumferential and radial stresses are, respectively, the maximum and minimum principal stresses. In other words, $\sigma_{1}=\sigma_{\theta}$ and $\sigma_{3}=\sigma_{\mathrm{r}}$, and substituting them into (4), the UST can be rewritten as

$$
\begin{aligned}
& \sigma_{\theta}=N_{\mathrm{p}} \sigma_{\mathrm{r}}+\sigma_{\mathrm{c}} \quad \text { for perfectly plastic stage, } \\
& \sigma_{\theta}=N_{\mathrm{p}} \sigma_{\mathrm{r}}+\overline{\sigma_{\mathrm{c}}}\left(\varepsilon_{1}^{\mathrm{p}}\right) \quad \text { for strain softening stage, } \\
& \sigma_{\theta}=N_{\mathrm{p}} \sigma_{\mathrm{r}}+\sigma_{\mathrm{c}}^{\mathrm{R}} \quad \text { for damage stage, }
\end{aligned}
$$

where $\sigma_{\mathrm{c}}^{\mathrm{R}}=\left(4(1+b) c_{\mathrm{r}} \cos \varphi\right) /((2+b)(1-\sin \varphi)) ; \quad \overline{\sigma_{\mathrm{c}}}\left(\varepsilon_{1}^{\mathrm{p}}\right)$ and $\varepsilon_{1}^{\mathrm{p}}$ represent the compressive strength and the maximum principal strain in the strain-softening zone, respectively; $c_{\mathrm{r}}$ represents residual cohesion. It should be noted that this paper assumes that the strain-softening process of rock mass is only related to the cohesion attenuation, which is independent of the internal friction angle.

2.3. Definition of Dilatancy Coefficient. As a natural geological body, many microcracks exist in the rock material, which make its post-peak stage appear nonlinear and dilatant, and then, the volume will also change. It is generally believed that the plastic deformation satisfies the nonassociated flow rule, determined by the plastic potential function $[8,10,11,22]$. The plastic potential function $f$ and the yield function $F^{\prime}$ have the same expression form. Therefore, this paper assumes that the plastic potential function is as follows:

$$
f\left(\sigma_{\theta i}, \sigma_{\mathrm{ri}}\right)=\sigma_{\theta i}-\eta_{i} \sigma_{\mathrm{r} i}
$$

where $\eta_{i}=\left(2+b+(2+3 b) \sin \psi_{i}\right) /\left((2+b)\left(1-\sin \psi_{i}\right)\right)$, in which $\psi_{i}$ represents the dilation angle in the " $i$ " zone.

According to the plastic potential theory, the relationship between stress and strain increment is satisfied:

$$
d \varepsilon_{i j}^{\mathrm{p}}=d \lambda \frac{\partial f}{\partial \sigma_{i j}},
$$

where $d \varepsilon_{i j}^{\mathrm{p}}$ and $\sigma_{i j}$ represent the plastic strain increment and stress tensor, respectively, and $d \lambda$ represents the nonnegative proportional constant. From (8) and (9), the plastic principal strain increment can be obtained as

$$
\begin{aligned}
& d \varepsilon_{\theta i}^{\mathrm{p}}=d \lambda \frac{\partial f}{\partial \sigma_{\theta i}}=d \lambda, \\
& d \varepsilon_{\mathrm{r} i}^{\mathrm{p}}=d \lambda \frac{\partial f}{\partial \sigma_{\mathrm{r} i}}=-\eta_{i} d \lambda .
\end{aligned}
$$

The dilatancy coefficient of the post-peak failure zone can be determined by the ratio of the minimum plastic principal strain increment to the maximum plastic principal strain increment. Then, the relationship between the plastic principle strain and the dilatancy coefficient is obtained as follows:

$$
\varepsilon_{\mathrm{r} i}^{\mathrm{p}}+\eta_{i} \varepsilon_{\theta i}^{\mathrm{p}}=0
$$

where $\varepsilon_{\mathrm{ri}}$ and $\varepsilon_{\theta i}$ are, respectively, the radial and tangential strain.

\section{Analytical Solution of EPSDM}

3.1. The Basic Equation. The equilibrium differential equation for the axisymmetric plane strain problem in the " $i$ " zone can be expressed as (ignoring the body force of rock mass)

$$
\frac{d \sigma_{\mathrm{ri}}}{d r}+\frac{\sigma_{\mathrm{ri}}-\sigma_{\theta i}}{r}=0
$$

The geometric equation, based on the small deformation assumption, can be denoted as

$$
\begin{gathered}
\varepsilon_{\mathrm{r} i}=\frac{d u_{\mathrm{r} i}}{d r}, \\
\varepsilon_{\theta i}=\frac{u_{\mathrm{r} i}}{r},
\end{gathered}
$$

where $u_{\mathrm{r} i}$ is the radial displacement of surrounding rock. The stress boundary conditions can be described as

$$
\begin{aligned}
& \sigma_{\text {re }}=\sigma_{0}, \quad(r \rightarrow \infty) \\
& \sigma_{\text {re }}=\sigma_{\text {rp }}, \quad\left(r=R_{\mathrm{p}}\right) \\
& \sigma_{\mathrm{rp}}=\sigma_{\mathrm{rs}}, \quad\left(r=R_{\mathrm{s}}\right) \text {. } \\
& \sigma_{\mathrm{rs}}=\sigma_{\mathrm{rc}}, \quad\left(r=R_{\mathrm{c}}\right) \\
& \sigma_{\mathrm{rs}}=p_{\text {in }}, \quad(r=a)
\end{aligned}
$$

3.2. Stresses and Displacement in the Elastic Zone. Based on the elasticity theory, the stress function for the axisymmetric plane strain problem in the elastic zone can be expressed as

$$
\Phi=A \ln r+B r^{2}
$$

where $A$ and $B$ are the unknown constants. The radial and tangential stresses are then given by

$$
\begin{gathered}
\sigma_{\mathrm{re}}=\frac{1}{r} \frac{d \phi}{d r}=\frac{A}{r^{2}}+2 B, \\
\sigma_{\theta \mathrm{e}}=\frac{d^{2} \phi}{d r^{2}}=-\frac{A}{r^{2}}+2 B .
\end{gathered}
$$

Substituting the boundary conditions $\sigma_{\text {re }}=\sigma_{0}$ at $r \rightarrow \infty$ and $\sigma_{\text {re }}=\sigma_{R_{\mathrm{p}}}$ at $r=R_{\mathrm{p}}$ into (5), where $\sigma_{R_{\mathrm{p}}}$ is the radial stress on the interface between the elastic zone and the perfectly 
plastic zone, the specific expressions of (16) and (17) can be obtained as

$$
\begin{gathered}
\sigma_{\text {re }}=\sigma_{0}+\left(\sigma_{R_{\mathrm{p}}}-\sigma_{0}\right) \frac{R_{\mathrm{p}}^{2}}{r^{2}}, \\
\sigma_{\theta \mathrm{e}}=\sigma_{0}-\left(\sigma_{R_{\mathrm{p}}}-\sigma_{0}\right) \frac{R_{\mathrm{p}}^{2}}{r^{2}} .
\end{gathered}
$$

The radial and tangential stresses in the elastic zone should satisfy (5) at $r=R_{\mathrm{p}}$. Thus, $\sigma_{R_{\mathrm{p}}}$ can be deduced by substituting (18) and (19) into (5):

$$
\sigma_{R_{\mathrm{p}}}=\frac{2 \sigma_{0}-\sigma_{\mathrm{c}}}{1+N_{\mathrm{p}}}
$$

According to the small deformation theory, the displacement and strain can also be expressed as follows [28]:

$$
\begin{aligned}
& u_{\mathrm{re}}=A_{0} \frac{R_{\mathrm{p}}^{2}}{r}, \\
& \varepsilon_{\mathrm{re}}=-A_{0} \frac{R_{\mathrm{p}}^{2}}{r^{2}}, \\
& \varepsilon_{\theta \mathrm{e}}=A_{0} \frac{R_{\mathrm{p}}^{2}}{r^{2}},
\end{aligned}
$$

where $A_{0}=(1+\nu)\left(\sigma_{0}-\sigma_{R_{\mathrm{p}}}\right) / E$. When $r=R_{\mathrm{p}}$, the displacement on the interface is

$$
u_{R_{\mathrm{p}}}=A_{0} R_{\mathrm{p}}
$$

3.3. Stresses and Displacement in the Perfectly Plastic Zone. Combined with the boundary condition $\sigma_{\mathrm{rp}}=\sigma_{R_{\mathrm{p}}}$ at $r=R_{\mathrm{p}}$, the stresses in the perfectly plastic zone can be derived by substituting (5) into (12):

$$
\begin{aligned}
\sigma_{\mathrm{rp}} & =\frac{2 \sigma_{0}\left(1-N_{\mathrm{p}}\right)-2 \sigma_{\mathrm{c}}}{1-N_{\mathrm{p}}^{2}}\left(\frac{r}{R_{\mathrm{p}}}\right)^{N_{\mathrm{p}}-1}+\frac{\sigma_{\mathrm{c}}}{1-N_{\mathrm{p}}}, \\
\sigma_{\theta \mathrm{p}} & =N_{\mathrm{p}} \frac{2 \sigma_{0}\left(1-N_{\mathrm{p}}\right)-2 \sigma_{\mathrm{c}}}{1-N_{\mathrm{p}}^{2}}\left(\frac{r}{R_{\mathrm{p}}}\right)^{N_{\mathrm{p}}-1}+\frac{\sigma_{\mathrm{c}}}{1-N_{\mathrm{p}}} .
\end{aligned}
$$

Then, the radial contact stress $\left(\sigma_{R_{\mathrm{s}}}\right)$ on the interface between the perfectly plastic zone and the strain-softening zone can be easily obtained by substituting $r=R_{\mathrm{s}}$ into (23):

$$
\sigma_{R_{\mathrm{s}}}=\frac{2 \sigma_{0}\left(1-N_{\mathrm{p}}\right)-2 \sigma_{\mathrm{c}}}{1-N_{\mathrm{p}}^{2}}\left(\frac{R_{\mathrm{s}}}{R_{\mathrm{p}}}\right)^{N_{\mathrm{p}}-1}+\frac{\sigma_{\mathrm{c}}}{1-N_{\mathrm{p}}} .
$$

Substituting (13) into (11), the differential equation of the radial displacement in the perfectly plastic zone should be given as

$$
\frac{d u_{\mathrm{rp}}}{d r}+\eta_{\mathrm{p}} \frac{u_{\mathrm{rp}}}{r}=0
$$

Solving (25), the displacement and strain can be deduced by considering the boundary condition $u_{\mathrm{rp}}=u_{R_{\mathrm{p}}}$ at $r=R_{\mathrm{p}}$ :

$$
\begin{aligned}
& u_{\mathrm{rp}}=A_{0} R_{\mathrm{p}}^{1+\eta_{\mathrm{p}}} r^{-\eta_{\mathrm{p}}}, \\
& \varepsilon_{\mathrm{rp}}=-A_{0} \eta_{\mathrm{p}} R_{\mathrm{p}}^{1+\eta_{\mathrm{p}}} r^{-\eta_{\mathrm{p}}-1}, \\
& \varepsilon_{\theta \mathrm{p}}=A_{0} R_{\mathrm{p}}^{1+\eta_{p}} r^{-\eta_{\mathrm{p}}-1} .
\end{aligned}
$$

When $\sigma_{0} \geq p_{\text {in }}$, the tangential strain is the maximum principal strain. Consequently, the displacement and maximum principal strain on the interface of the perfectly plastic strain-softening zone can be obtained by substituting $r=R_{\mathrm{s}}$ into (26) as follows:

$$
\begin{gathered}
u_{R_{\mathrm{s}}}=A_{0} R_{\mathrm{p}}^{1+\eta_{\mathrm{p}}} R_{\mathrm{s}}^{-\eta_{\mathrm{p}}}, \\
\varepsilon_{\mathrm{s}}^{\text {Peak }}=A_{0} R_{\mathrm{p}}^{1+\eta_{\mathrm{p}}} R_{\mathrm{s}}^{-\eta_{\mathrm{p}}-1} .
\end{gathered}
$$

3.4. Stresses and Displacement in the Strain-Softening Zone. Based on the calculation method of the perfectly plastic zone, combined with the boundary condition $u_{\mathrm{rs}}=$ $u_{R_{\mathrm{s}}}$ at $r=R_{\mathrm{s}}$, we can easily get the expressions of the displacement and strain in the strain-softening zone:

$$
\begin{aligned}
& u_{\mathrm{rs}}=A_{0} R_{\mathrm{p}}^{1+\eta_{\mathrm{p}}} R_{\mathrm{s}}^{\eta_{\mathrm{s}}-\eta_{\mathrm{p}}} r^{-\eta_{\mathrm{s}}}, \\
& \varepsilon_{\mathrm{rs}}=-A_{0} \eta_{\mathrm{s}} R_{\mathrm{p}}^{1+\eta_{\mathrm{p}}} R_{\mathrm{s}}^{\eta_{\mathrm{s}}-\eta_{\mathrm{p}}} r^{-\eta_{\mathrm{s}}-1}, \\
& \varepsilon_{\theta \mathrm{s}}=A_{0} R_{\mathrm{p}}^{1+\eta_{\mathrm{p}}} R_{\mathrm{s}}^{\eta_{\mathrm{s}}-\eta_{\mathrm{p}}} r^{-\eta_{\mathrm{s}}-1} .
\end{aligned}
$$

According to (29), the radial displacement on the interface between the strain-softening zone and the damage zone can also be obtained easily:

$$
u_{R_{\mathrm{c}}}=A_{0} R_{\mathrm{p}}^{1+\eta_{\mathrm{p}}} R_{\mathrm{s}}^{\eta_{\mathrm{s}}-\eta_{\mathrm{p}}} R_{\mathrm{c}}^{-\eta_{\mathrm{s}}} .
$$

In the strain-softening zone, it is assumed that the strength attenuation of rock mass is only related to cohesion (c). Then, the compressive strength at any point can be expressed as

$$
\overline{\sigma_{\mathrm{c}}}\left(\varepsilon_{1}^{\mathrm{p}}\right)=\sigma_{\mathrm{c}}-\beta(1+\nu)\left(\sigma_{0}-\sigma_{R_{\mathrm{p}}}\right)\left[\varepsilon_{\theta \mathrm{s}}(r)-\varepsilon_{\mathrm{s}}^{\text {Peak }}\right],
$$

where $\beta=\tan \theta / E$, which can be defined as a strainsoftening coefficient. $\tan \theta$ may be called the strain-softening modulus, which can be determined by the slope of the "BC" segment in Figure 3. E is Young's modulus, which can be determined by the slope of the "OA" segment. Therefore, the parameter $\beta$ can be determined by the ratio of the slope of the "BC" segment to the slope of the "OA" segment in Figure 3. Introducing (28) and (29) into (31), it can be rewritten as

$$
\overline{\sigma_{\mathrm{c}}}=\sigma_{\mathrm{c}}-\beta(1+\nu)\left(\sigma_{0}-\sigma_{R_{\mathrm{p}}}\right) R_{\mathrm{p}}^{1+\eta_{\mathrm{p}}} R_{\mathrm{s}}^{-\eta_{\mathrm{p}}-1}\left[\left(\frac{R_{\mathrm{s}}}{r}\right)^{1+\eta_{\mathrm{s}}}-1\right] \text {. }
$$

Combined with the boundary condition $\sigma_{\mathrm{rs}}=\sigma_{R_{\mathrm{s}}}$ at $r=R_{\mathrm{s}}$, the stresses in the strain-softening zone can be derived by substituting (32) and (6) into the equilibrium equation (12): 


$$
\begin{aligned}
& \sigma_{\mathrm{rs}}=\frac{2 \sigma_{0}\left(1-N_{\mathrm{p}}\right)-2 \sigma_{\mathrm{c}}}{1-N_{\mathrm{p}}^{2}}\left(\frac{R_{\mathrm{p}}}{r}\right)^{1-N_{\mathrm{p}}}+\frac{\sigma_{\mathrm{c}}}{1-N_{\mathrm{p}}}+\frac{\beta(1+\nu)\left(\sigma_{0}-\sigma_{R_{\mathrm{p}}}\right)}{\eta_{\mathrm{s}}+N_{\mathrm{p}}}\left(\frac{R_{\mathrm{p}}}{R_{\mathrm{s}}}\right)^{1+\eta_{\mathrm{p}}}\left[\left(\frac{R_{\mathrm{s}}}{r}\right)^{1+\eta_{\mathrm{s}}}-\left(\frac{R_{\mathrm{s}}}{r}\right)^{1-N_{\mathrm{p}}}\right] \\
& +\frac{\beta(1+v)\left(\sigma_{0}-\sigma_{R_{\mathrm{p}}}\right)}{1-N_{\mathrm{p}}}\left(\frac{R_{\mathrm{p}}}{R_{\mathrm{s}}}\right)^{1+\eta_{\mathrm{p}}}\left[1-\left(\frac{R_{\mathrm{s}}}{r}\right)^{1-N_{\mathrm{p}}}\right] \\
& \sigma_{\theta \mathrm{s}}=N_{\mathrm{p}}\left\{\frac{2 \sigma_{0}\left(1-N_{\mathrm{p}}\right)-2 \sigma_{\mathrm{c}}}{1-N_{\mathrm{p}}^{2}}\left(\frac{R_{\mathrm{p}}}{r}\right)^{1-N_{\mathrm{p}}}+\frac{\sigma_{\mathrm{c}}}{1-N_{\mathrm{p}}}+\frac{\beta(1+\nu)\left(\sigma_{0}-\sigma_{R_{\mathrm{p}}}\right)}{\eta_{\mathrm{s}}+N_{\mathrm{p}}}\left(\frac{R_{\mathrm{p}}}{R_{\mathrm{s}}}\right)^{1+\eta_{\mathrm{p}}}\left[\left(\frac{R_{\mathrm{s}}}{r}\right)^{1+\eta_{\mathrm{s}}}-\left(\frac{R_{\mathrm{s}}}{r}\right)^{1-N_{\mathrm{p}}}\right]\right. \\
& \left.+\frac{\beta(1+\nu)\left(\sigma_{0}-\sigma_{R_{\mathrm{p}}}\right)}{1-N_{\mathrm{p}}}\left(\frac{R_{\mathrm{p}}}{R_{\mathrm{s}}}\right)^{1+\eta_{\mathrm{p}}}\left[1-\left(\frac{R_{\mathrm{s}}}{r}\right)^{1-N_{\mathrm{p}}}\right]\right\}+\sigma_{\mathrm{c}}-\beta(1+\nu)\left(\sigma_{0}-\sigma_{R_{\mathrm{p}}}\right)\left(\frac{R_{\mathrm{p}}}{R_{\mathrm{s}}}\right)^{1+\eta_{\mathrm{p}}}\left[\left(\frac{R_{\mathrm{s}}}{r}\right)^{1+\eta_{\mathrm{s}}}-1\right] .
\end{aligned}
$$

3.5. Stresses and Displacement in the Damage Zone. Introducing (7) into the equilibrium equation (12), the stresses in the damage zone can be solved by considering the boundary condition $\sigma_{\mathrm{rc}}=p_{\text {in }}$ at $r=a$ :

$$
\begin{aligned}
& \sigma_{\mathrm{rc}}=\frac{\left(1-N_{\mathrm{p}}\right) p_{\mathrm{in}}-\sigma_{\mathrm{c}}^{\mathrm{R}}}{1-N_{\mathrm{p}}}\left(\frac{r}{a}\right)^{N_{\mathrm{p}}-1}+\frac{\sigma_{\mathrm{c}}^{\mathrm{R}}}{1-N_{\mathrm{p}}}, \\
& \sigma_{\theta \mathrm{c}}=N_{\mathrm{p}} \frac{\left(1-N_{\mathrm{p}}\right) p_{\mathrm{in}}-\sigma_{\mathrm{c}}^{\mathrm{R}}}{1-N_{\mathrm{p}}}\left(\frac{r}{a}\right)^{N_{\mathrm{p}}-1}+\frac{\sigma_{\mathrm{c}}^{\mathrm{R}}}{1-N_{\mathrm{p}}} .
\end{aligned}
$$

As shown in (29), combined with the boundary condition $\left(u_{\mathrm{rc}}\right)_{r=R_{\mathrm{c}}}=u_{R_{\mathrm{c}}}$, the displacement and strain in the damage zone can also be expressed as

$$
\begin{aligned}
& u_{\mathrm{rc}}=A_{0} R_{\mathrm{p}}^{1+\eta_{\mathrm{p}}} R_{\mathrm{s}}^{\eta_{\mathrm{s}}-\eta_{\mathrm{p}}} R_{\mathrm{c}}^{\eta_{\mathrm{c}}-\eta_{\mathrm{s}}} r^{-\eta_{\mathrm{c}}}, \\
& \varepsilon_{\mathrm{rc}}=-\eta_{\mathrm{c}} A_{0} R_{\mathrm{p}}^{1+\eta_{\mathrm{p}}} R_{\mathrm{s}}^{\eta_{\mathrm{s}}-\eta_{\mathrm{p}}} R_{\mathrm{c}}^{\eta_{\mathrm{c}}-\eta_{\mathrm{s}}} r^{-\eta_{\mathrm{c}}-1}, \\
& \varepsilon_{\theta \mathrm{c}}=A_{0} R_{\mathrm{p}}^{1+\eta_{\mathrm{p}}} R_{\mathrm{s}}^{\eta_{\mathrm{s}}-\eta_{\mathrm{p}}} R_{\mathrm{c}}^{\eta_{\mathrm{c}}-\eta_{\mathrm{s}}} r^{-\eta_{\mathrm{c}}-1} .
\end{aligned}
$$

According to (35a), when $r=a$, the surface displacement of surrounding rock is as follows:

$$
u_{0}=A_{0} R_{\mathrm{p}}^{1+\eta_{\mathrm{p}}} R_{\mathrm{s}}^{\eta_{\mathrm{s}}-\eta_{\mathrm{p}}} R_{\mathrm{c}}^{\eta_{\mathrm{c}}-\eta_{\mathrm{s}}} a^{-\eta_{\mathrm{c}}} .
$$

3.6. The Radius of the Post-Peak Failure Zone $\left(R_{p}, R_{s}\right.$, and $R_{c}$ ). In order to obtain the closed solution of the stresses and deformation of the EPSDM, the post-peak failure zone radii $\left(R_{\mathrm{c}}, R_{\mathrm{s}}\right.$, and $\left.R_{\mathrm{p}}\right)$ should be firstly determined. According to the relationship among $R_{\mathrm{p}}, R_{\mathrm{s}}$, and $R_{\mathrm{c}}$, the EPSDM can be converted to the following 5 cases including its original form.

Case 1. From (32), when $\beta=0$ and $\overline{\sigma_{c}}=\sigma_{c}=\sigma_{c}^{R}$, the post-peak failure radii satisfy the relation $a=R_{\mathrm{c}}=R_{\mathrm{s}}<R_{\mathrm{p}}$, and then, the surrounding rock only consists of the elastic zone and the perfectly plastic zone. Therefore, the EPSDM's solution can be converted to the EPM's result. Combining with (23) and the stress boundary condition $\left(\sigma_{\mathrm{rp}}\right)_{r=a}=p_{\text {in }}$, the perfectly plastic zone radius $R_{\mathrm{p}}$ can be obtained:

$$
R_{\mathrm{p}}=a\left(\frac{p_{\text {in }}-\left(\sigma_{\mathrm{c}} /\left(1-N_{\mathrm{p}}\right)\right)}{\left(2 \sigma_{0}\left(1-N_{\mathrm{p}}\right)-2 \sigma_{\mathrm{c}}\right) /\left(1-N_{\mathrm{p}}^{2}\right)}\right)^{1 /\left(1-N_{\mathrm{p}}\right)} .
$$

Case 2. When $a<R_{\mathrm{c}}<R_{\mathrm{s}}<R_{\mathrm{p}}$, in order to get the closed solution of $R_{\mathrm{p}}, R_{\mathrm{s}}$, and $R_{\mathrm{c}}$, it is required to establish three linear independent equations to solve the problem. According to the stress contact condition $\left(\sigma_{\mathrm{rs}}\right)_{r=R_{\mathrm{c}}}=\left(\sigma_{\mathrm{rc}}\right)_{r=R_{\mathrm{c}}}$, one of the relationships can be established by combining with (33) and (34):

$$
\begin{gathered}
\frac{2 \sigma_{0}\left(1-N_{\mathrm{p}}\right)-2 \sigma_{\mathrm{c}}}{1-N_{\mathrm{p}}^{2}}\left(\frac{R_{\mathrm{p}}}{R_{\mathrm{c}}}\right)^{1-N_{\mathrm{p}}}+\frac{\sigma_{\mathrm{c}}}{1-N_{\mathrm{p}}}+\frac{\beta(1+\nu)\left(\sigma_{0}-\sigma_{R_{\mathrm{p}}}\right)}{\eta_{\mathrm{s}}+N_{\mathrm{p}}}\left(\frac{R_{\mathrm{p}}}{R_{\mathrm{s}}}\right)^{1+\eta_{\mathrm{p}}}\left(\frac{R_{\mathrm{s}}}{R_{\mathrm{c}}}\right)^{1+\eta_{\mathrm{s}}}\left[1-\left(\frac{R_{\mathrm{s}}}{R_{\mathrm{c}}}\right)^{-\eta_{\mathrm{s}}-N_{\mathrm{p}}}\right] \\
+\frac{\beta(1+\nu)\left(\sigma_{0}-\sigma_{R_{\mathrm{p}}}\right)}{1-N_{\mathrm{p}}}\left(\frac{R_{\mathrm{p}}}{R_{\mathrm{s}}}\right)^{1+\eta_{\mathrm{p}}}\left[1-\left(\frac{R_{\mathrm{s}}}{R_{\mathrm{c}}}\right)^{1-N_{\mathrm{p}}}\right]-\frac{\left(1-N_{\mathrm{p}}\right) p_{\mathrm{in}}-\sigma_{\mathrm{c}}^{\mathrm{R}}}{1-N_{\mathrm{p}}}\left(\frac{R_{\mathrm{c}}}{a}\right)^{N_{\mathrm{p}}-1}-\frac{\sigma_{\mathrm{c}}^{\mathrm{R}}}{1-N_{\mathrm{p}}}=0 .
\end{gathered}
$$

Then, the slope of the line "BC" in the strain-softening zone can be expressed as

$$
\tan \theta=\frac{\sigma_{\mathrm{c}}-\sigma_{\mathrm{c}}^{\mathrm{R}}}{\varepsilon_{\mathrm{c}}^{\mathrm{R}}-\varepsilon_{\mathrm{s}}^{\text {Peak }}}=\frac{\sigma_{\mathrm{c}}-\sigma_{\mathrm{c}}^{\mathrm{R}}}{A_{0}\left(R_{\mathrm{p}} / R_{\mathrm{s}}\right)^{1+\eta_{\mathrm{p}}}\left[\left(R_{\mathrm{s}} / R_{\mathrm{c}}\right)^{1+\eta_{\mathrm{s}}}-1\right]} .
$$

Apart from (37) and (38), a new condition is still needed to make the EPSDM form a closed solution. It is generally believed that the extension of the perfectly plastic zone is not infinite and will be restricted by other conditions. Zhang et al. [11] consider that when the plastic shear strain or the equivalent plastic shear strain reaches a critical value, the 
rock mass begins to enter the damage zone; Wei et al. and Jiang et al. [32,33] believe that another relationship between $R_{\mathrm{p}}$ and $R_{\mathrm{c}}$ may be established by the radial strain continuous condition $\left(\varepsilon_{\mathrm{rc}}\right)_{r=R_{\mathrm{c}}}=\left(\varepsilon_{\mathrm{rp}}\right)_{r=R_{\mathrm{c}}}$. In this paper, it is assumed that when the plastic shear stress increment $\Delta \gamma^{*}$ between the yield points "A" and "B" (Figure 3 ) reaches a certain value, the rock mass starts to enter the strain-softening state. Accordingly, the other relationship among $R_{\mathrm{p}}, R_{\mathrm{s}}$, and $R_{\mathrm{c}}$ can be expressed as

$$
\Delta \gamma^{*}=\gamma_{\mathrm{s}}^{*}-\gamma_{\mathrm{p}}^{*}=\left(\varepsilon_{\theta \mathrm{p}}-\varepsilon_{\mathrm{rp}}\right)_{r=R_{\mathrm{s}}}-\left(\varepsilon_{\theta \mathrm{p}}-\varepsilon_{\mathrm{rp}}\right)_{r=R_{\mathrm{p}}},
$$

where $\gamma_{\mathrm{s}}^{*}$ and $\gamma_{\mathrm{p}}^{*}$ represent the plastic shear strain at points "B" and "A," respectively. As shown in Figure 3, in the triaxial test, the maximum and minimum principal strain of rock mass can be easily obtained, and then, $\gamma_{\mathrm{s}}^{*}=\varepsilon_{\mathrm{s}}^{\text {Peak }}-\varepsilon_{\mathrm{ss}}^{\text {Peak }}$ and $\gamma_{\mathrm{p}}^{*}=$ $\varepsilon_{\mathrm{p}}^{\text {Peak }}-\varepsilon_{\mathrm{pp}}^{\text {Peak }}$. In addition, $\varepsilon_{\mathrm{ss}}^{\text {Peak }}$ and $\varepsilon_{\mathrm{pp}}^{\text {Peak }}$ represent the minimum principal strain at the points " $\mathrm{B}$ " and "A," respectively.
Substituting (26) into (41), it can be rewritten as

$$
R_{\mathrm{p}}=\left[\frac{\Delta \gamma^{*}}{A_{0}\left(1+\eta_{\mathrm{p}}\right)}+1\right]^{1 /\left(1+\eta_{\mathrm{p}}\right)} R_{\mathrm{s}}=T R_{\mathrm{s}},
$$

where $T=\left[\left(\Delta \gamma^{*} /\left(A_{0}\left(1+\eta_{\mathrm{p}}\right)\right)\right)+1\right]^{1 /\left(1+\eta_{\mathrm{p}}\right)}$.

Substituting (40) into (38), the following expression can also be obtained:

$$
R_{\mathrm{s}}=\left(\frac{\sigma_{\mathrm{c}}-\sigma_{\mathrm{c}}^{\mathrm{R}}}{\beta(1+\nu)\left(\sigma_{0}-\sigma_{R_{\mathrm{p}}}\right) T^{1+\eta_{\mathrm{p}}}}+1\right)^{1 /\left(1+\eta_{\mathrm{s}}\right)} R_{\mathrm{c}}=t R_{\mathrm{c}}
$$

where $t=\left(\left(\sigma_{\mathrm{c}}-\sigma_{\mathrm{c}}^{\mathrm{R}}\right) /\left(\beta(1+v)\left(\sigma_{0}-\sigma_{R_{\mathrm{p}}}\right) T^{1+\eta_{\mathrm{p}}}\right)\right)^{1 /\left(1+\eta_{\mathrm{s}}\right)}$.

Substituting (40) and (41) into (37), the damage zone radius is expressed as

$$
\begin{aligned}
R_{\mathrm{c}}= & a\left\{\left[\left[\left(\left(\left(2 \sigma_{0}\left(1-N_{\mathrm{p}}\right)-2 \sigma_{\mathrm{c}}\right) /\left(1-N_{\mathrm{p}}^{2}\right)\right) T^{1-N_{\mathrm{p}}}\right)-\left(\left(\left(\beta(1+\nu)\left(\sigma_{0}-\sigma_{R_{\mathrm{p}}}\right)\right) /\left(\eta_{\mathrm{s}}+N_{\mathrm{p}}\right)\right)+\left(\left(\beta(1+\nu)\left(\sigma_{0}-\sigma_{R_{\mathrm{p}}}\right)\right) /\left(1-N_{\mathrm{p}}\right)\right)\right) T^{1+\eta_{\mathrm{p}}}\right] t^{1-N_{\mathrm{p}}}\right.\right. \\
& \left.+\left(\left(\left(\beta(1+\nu)\left(\sigma_{0}-\sigma_{R_{\mathrm{p}}}\right)\right) /\left(\eta_{\mathrm{s}}+N_{\mathrm{p}}\right)\right) t^{1+\eta_{\mathrm{s}}}+\left(\left(\beta(1+\nu)\left(\sigma_{0}-\sigma_{R_{\mathrm{p}}}\right)\right) /\left(1-N_{\mathrm{p}}\right)\right)\right) T^{1+\eta_{\mathrm{p}}}+\left(\left(\sigma_{\mathrm{c}}-\sigma_{\mathrm{c}}^{\mathrm{R}}\right) /\left(1-N_{\mathrm{p}}\right)\right)\right] \\
& \left.\times\left\{\left(\left(1-N_{\mathrm{p}}\right) p_{\text {in }}-\sigma_{\mathrm{c}}^{\mathrm{R}}\right) /\left(1-N_{\mathrm{p}}\right)\right\}^{-1}\right\}^{1 /\left(N_{\mathrm{p}}-1\right)}
\end{aligned}
$$

Subsequently, the radii $R_{\mathrm{s}}$ and $R_{\mathrm{p}}$ can also be obtained by substituting (42) into (41) and (40), respectively.

Case 3. From (40), when $\Delta \gamma^{*}=0$, the limit of $T$ is equal to one. Then, the post-peak failure radii satisfy the relation $a<R_{\mathrm{c}}<R_{\mathrm{s}}=R_{\mathrm{p}}$, and the surrounding rock is composed of the elastic zone, strain-softening zone, and damage zone. Therefore, the EPSDM's solution is converted to the ESM's result. Combining with (41) and (42), the radius expression of $R_{\mathrm{c}}$ and $R_{\mathrm{s}}$ can be deduced:

$$
\begin{gathered}
R_{\mathrm{c}}=a\left[\begin{array}{l}
\delta_{1}\left(\left(\left(\sigma_{\mathrm{c}}-\sigma_{\mathrm{c}}^{\mathrm{R}}\right) /\left(\beta(1+\nu)\left(\sigma_{0}-\sigma_{R_{\mathrm{p}}}\right)\right)\right)+1\right)^{\left(1-N_{\mathrm{p}}\right) /\left(1+\eta_{\mathrm{s}}\right)} \\
+\left(\left(\beta(1+\nu)\left(\sigma_{0}-\sigma_{R_{\mathrm{p}}}\right)\right) /\left(\eta_{\mathrm{s}}+N_{\mathrm{p}}\right)\right)\left(\left(\left(\sigma_{\mathrm{c}}-\sigma_{\mathrm{c}}^{\mathrm{R}}\right) /\left(\beta(1+\nu)\left(\sigma_{0}-\sigma_{R_{\mathrm{p}}}\right)\right)\right)+1\right)+\delta_{2} \\
\left(\left(1-N_{\mathrm{p}}\right) p_{\mathrm{in}}-\sigma_{\mathrm{c}}^{\mathrm{R}}\right) /\left(1-N_{\mathrm{p}}\right)
\end{array}\right]^{1 /\left(N_{\mathrm{p}}-1\right)}, \\
R_{\mathrm{s}}=a\left(\frac{\sigma_{\mathrm{c}}-\sigma_{\mathrm{c}}^{\mathrm{R}}}{\beta(1+\nu)\left(\sigma_{0}-\sigma_{R_{\mathrm{p}}}\right)}+1\right)^{1 /\left(1+\eta_{\mathrm{s}}\right)}\left[\begin{array}{l}
\delta_{1}\left(\left(\left(\sigma_{\mathrm{c}}-\sigma_{\mathrm{c}}^{\mathrm{R}}\right) / \beta(1+\nu)\left(\sigma_{0}-\sigma_{R_{\mathrm{p}}}\right)\right)+1\right)^{\left(1-N_{\mathrm{p}}\right) /\left(1+\eta_{\mathrm{s}}\right)} \\
+\left(\left(\beta(1+\nu)\left(\sigma_{0}-\sigma_{R_{\mathrm{p}}}\right)\right) /\left(\eta_{\mathrm{s}}+N_{\mathrm{p}}\right)\right)\left(\left(\left(\sigma_{\mathrm{c}}-\sigma_{\mathrm{c}}^{\mathrm{R}}\right) /\left(\beta(1+\nu)\left(\sigma_{0}-\sigma_{R_{\mathrm{p}}}\right)\right)\right)+1\right)+\delta_{2} \\
\left(\left(1-N_{\mathrm{p}}\right) p_{\mathrm{in}}-\sigma_{\mathrm{c}}^{\mathrm{R}}\right) /\left(1-N_{\mathrm{p}}\right)
\end{array}\right]
\end{gathered}
$$

where $\delta_{1}=\left(\left(2 \sigma_{0}\left(1-N_{\mathrm{p}}\right)-2 \sigma_{\mathrm{c}}\right) /\left(1-N_{\mathrm{p}}^{2}\right)\right)-\left(\left(\beta(1+\nu)\left(\sigma_{0}-\right.\right.\right.$ $\left.\left.\left.\sigma_{R_{\mathrm{p}}}\right)\right) /\left(\eta_{\mathrm{s}}+N_{\mathrm{p}}\right)\right)-\left(\left(\beta(1+\nu)\left(\sigma_{0}-\sigma_{R_{\mathrm{p}}}\right)\right) /\left(1-N_{\mathrm{p}}\right)\right)$ and $\delta_{2}=$ $\left(\sigma_{\mathrm{c}}-\sigma_{\mathrm{c}}^{\mathrm{R}}+\beta(1+\nu)\left(\sigma_{0}-\sigma_{R_{\mathrm{p}}}\right)\right) /\left(1-N_{\mathrm{p}}^{\mathrm{p}}\right)$.

Case 4. From (41), when $\beta \rightarrow \infty$, the limit of $t$ is equal to one. Then, the post-peak failure zone radii satisfy the relation
$a<R_{\mathrm{c}}=R_{\mathrm{s}}<R_{\mathrm{p}}$, and the surrounding rock is parted into three zones: the elastic zone, perfectly plastic zone, and damage zone. Therefore, the EPSDM's solution is converted to the EPBM's result. Combining with (40) and (42), the post-peak failure radii $R_{\mathrm{p}}$ and $R_{\mathrm{c}}$ can be obtained as follows: 


$$
\begin{aligned}
& R_{\mathrm{c}}=a\left[\begin{array}{l}
\left(\left(\left(2 \sigma_{0}\left(1-N_{\mathrm{p}}\right)-2 \sigma_{\mathrm{c}}\right) /\left(1-N_{\mathrm{p}}^{2}\right)\right) T^{1-N_{\mathrm{p}}}\right) \\
\frac{+\left(\left(\sigma_{\mathrm{c}}-\sigma_{\mathrm{c}}^{\mathrm{R}}\right) /\left(1-N_{\mathrm{p}}\right)\right)}{\left(\left(1-N_{\mathrm{p}}\right) p_{\text {in }}-\sigma_{\mathrm{c}}^{\mathrm{R}}\right) /\left(1-N_{\mathrm{p}}\right)}
\end{array}\right]^{1 /\left(N_{\mathrm{p}}-1\right)}, \\
& R_{\mathrm{p}}=a T\left[\begin{array}{l}
\left(\left(\left(2 \sigma_{0}\left(1-N_{\mathrm{p}}\right)-2 \sigma_{\mathrm{c}}\right) /\left(1-N_{\mathrm{p}}^{2}\right)\right) T^{1-N_{\mathrm{p}}}\right) \\
\frac{+\left(\left(\sigma_{\mathrm{c}}-\sigma_{\mathrm{c}}^{\mathrm{R}}\right) /\left(1-N_{\mathrm{p}}\right)\right)}{\left(\left(1-N_{\mathrm{p}}\right) p_{\text {in }}-\sigma_{\mathrm{c}}^{\mathrm{R}}\right) /\left(1-N_{\mathrm{p}}\right)}
\end{array}\right]^{1 /\left(N_{\mathrm{p}}-1\right)} .
\end{aligned}
$$

Case 5. When $\Delta \gamma^{*}=0$ and $\beta \rightarrow \infty$, the limit of $T$ and $t$ is equal to one. Then, the post-peak failure radii satisfy the relation $a<R_{\mathrm{s}}=R_{\mathrm{c}}=R_{\mathrm{p}}$, and the surrounding rock only includes the elastic zone and damage zone. Therefore, the EPSDM's solution is converted to the EBM's result. According to (42), the damage zone radius $R_{\mathrm{c}}$ will be given as

$$
R_{\mathrm{c}}=a\left\{\frac{2 \sigma_{0}-\sigma_{\mathrm{c}}-\left(\left(\left(1+N_{\mathrm{p}}\right) \sigma_{\mathrm{c}}^{\mathrm{R}}\right) /\left(1-N_{\mathrm{p}}\right)\right)}{\left(\left(1+N_{\mathrm{p}}\right)\left[\left(1-N_{\mathrm{p}}\right) p_{\text {in }}-\sigma_{\mathrm{c}}^{\mathrm{R}}\right]\right) /\left(1-N_{\mathrm{p}}\right)}\right\}^{1 /\left(N_{\mathrm{p}}-1\right)} .
$$

\section{Comparative Analysis}

4.1. Transformation Relationship between EPSDM and the Other Models. Compared with the traditional solution, the influences of intermediate principal stress and the dilatancy coefficient on the surrounding rock state are considered. The solutions based on M-C and GTSS yield criteria can be generated from the new closed-form solution using $b=0$ and $b=1.0$, respectively. In addition, compared with the traditional EBM, EPM, ESM, and EPBM, the EPSDM includes all the features of the above models. When $\beta=0$, the model is transformed into the EPM. When $\Delta \gamma^{*}=0$ and $\beta \rightarrow \infty$, the model is transformed into the EBM. Only when $\Delta \gamma^{*}=0$, the model is transformed into the ESM. Only when $\beta \rightarrow \infty$, the model is transformed into the EPBM. Therefore, the EPSDM has more extensive practicality and theoretical values than other models.

Detournay [1], $\mathrm{Xu}$ and $\mathrm{Yu}$ [15], and Li et al. [28] all studied the same issue, but Detournay's solution based on the M-C yield criterion neglected the influence of intermediate principal stress, whereas the solutions by $\mathrm{Xu}$ and Li neglected the influence of rock dilatancy on the radial displacement. Therefore, the solution may have a large deviation between the calculation results and the practical situation. This paper takes account of the intermediate principal stress and the dilation. When $b=0, \eta_{\mathrm{c}}=\eta_{\mathrm{s}}=$ $\eta_{\mathrm{p}}=1.0$, and $\Delta \gamma^{*}=0$, the EPSDM's solution is Li et al.'s solution [28]. When $\beta=0$ and $\eta_{\mathrm{c}}=\eta_{\mathrm{s}}=\eta_{\mathrm{p}}=1.0$, the EPSDM's solution is Xu and Yu's result [15]. Therefore, the solutions by $\mathrm{Xu}$ and $\mathrm{Li}$ are all special cases of this paper.
TABLe 1: Geometrical and physical parameters of the circular tunnel.

\begin{tabular}{lc}
\hline Parameters & $\begin{array}{c}\text { Values from Pan's } \\
\text { research [23] }\end{array}$ \\
\hline Radius of the opening, $a(\mathrm{~m})$ & 10 \\
Initial stress, $\sigma_{0}(\mathrm{MPa})$ & 30 \\
Internal pressure, $p_{\text {in }}(\mathrm{MPa})$ & 0 \\
Young's modulus, $E(\mathrm{MPa})$ & 2000 \\
Dilation coefficient, $\eta_{i}$ & 3.0 \\
Poisson's ratio, $v$ & 0.3 \\
Initial cohesion, $c(\mathrm{MPa})$ & 6 \\
Residual cohesion, $c_{\mathrm{r}}(\mathrm{MPa})$ & 6 \\
Strain-softening factor, $\beta(\mathrm{MPa})$ & 0 \\
Internal friction angle, $\varphi\left(^{\circ}\right)$ & 30 \\
\hline
\end{tabular}

4.2. Validation of Model Correctness. Based on the elastoperfectly plastic constitutive model, Pan et al. [23] introduced the UST into the finite element program ABAQUS and then researched the stress distribution of surrounding rock in the deep circular tunnel with $b=0,0.5$, and 1.0. The simulated rock material and model geometry parameters are shown in Table 1 . To satisfy the numerical simulation conditions, the calculation uses the associated flow law $\left(\psi_{i}=\varphi_{i}\right), \beta=0$, and $\eta_{i}=\left(1+\sin \psi_{i}\right) /\left(1-\sin \psi_{i}\right)$. The comparison between the calculation and simulation results is shown in Figure 4.

It can be seen from Figure 4 that the stress distribution around the circular tunnel is basically consistent with the Pan's numerical simulation results $(b=0,0.5$, and 1.0). Therefore, it confirms the correctness of the stress solution.

\section{Example Study}

5.1. Case I: Stress and Deformation Evolution Law of the EPSDM. The stresses and deformation are the important basis for evaluating the stability of surrounding rock and the reliability of support design. In order to study the evolution law of stresses and displacement under different constitutive models, the mechanical and geometrical parameters of soft rock are shown in Table 2, which is available by Ogawa and Lo [2]. In addition, $b=0, \Delta \gamma^{*}=2.5 \times 10^{-5}$, and $\beta=2.5$.

The stress distribution of the EPSDM under different critical support resistance is shown in Figure 5. As shown in Table 3 and Figure 5, it can be seen that when $p_{\text {in }} / \sigma_{0} \geq 0.200$, the rock mass only consists of the elastic zone. When $0.152 \leq p_{\text {in }} / \sigma_{0}<0.200$, the perfectly plastic zone begins to occur, and then, the rock mass is composed of the elastic zone and the perfectly plastic zone. While $0.028 \leq p_{\text {in }} / \sigma_{0}<0.152$, the strain-softening zone is gradually formed and the rock mass is composed of three parts: the elastic zone, perfectly plastic zone, and strain-softening zone. Once $p_{\text {in }} / \sigma_{0}<0.028$, the damaged zone begins to develop and the rock mass finally displays four zones: elastic zone, perfectly plastic zone, strainsoftening zone, and damage zone.

Figures 6 and 7 illustrate the influence of support resistance on the post-peak failure radii $\left(R_{\mathrm{p}}, R_{\mathrm{s}}\right.$, and $\left.R_{\mathrm{c}}\right)$ and surface displacement. In addition, when $p_{\text {in }}=0$, the postpeak failure radii and surface displacement are as shown in 


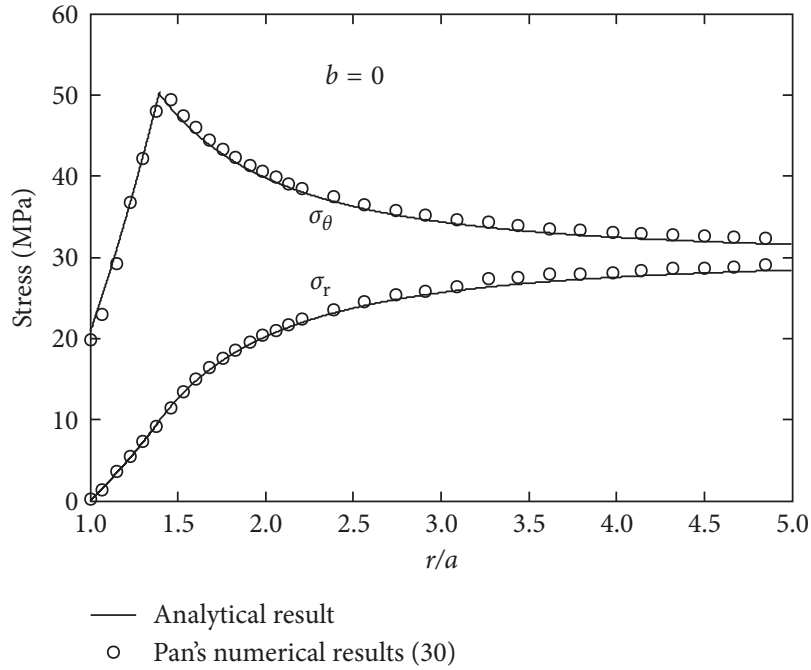

(a)

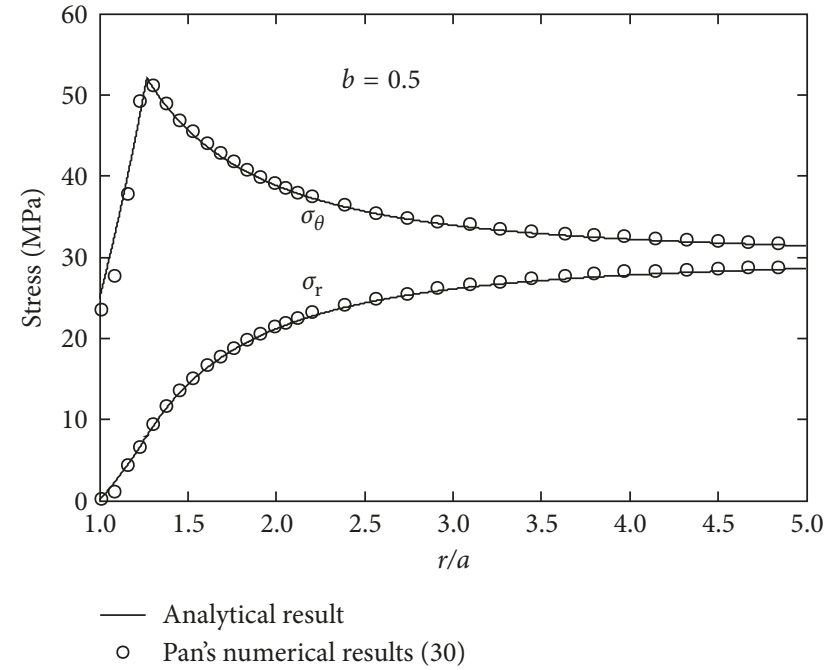

(b)

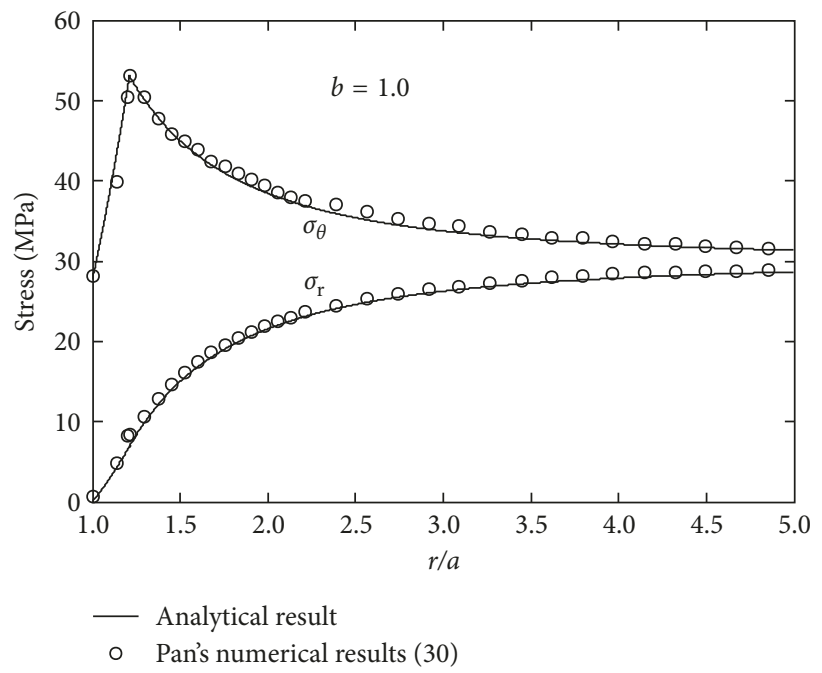

(c)

FIGURE 4: Contrast of stress distribution.

Table 4. From the above two figures, it can be seen that once the support resistance satisfies $0.152 \leq p_{\text {in }} / \sigma_{0}<0.200$, the calculated results based on the EPSDM are the same as those of the EPM and EPBM. However, once the plastic shear strain increment is larger than the critical plastic shear strain increment, $\Delta \gamma^{*}=2.5 \times 10^{-5}$, and then, the strain-softening zone begins to develop. When the residual cohesion reaches a residual value, $p_{\text {in }} / \sigma_{0}=0.028$ and the rock mass begins to enter the damage stage. As the support resistance is completely released, then $R_{\mathrm{p}} / a=1.165$ for the EPM; $R_{\mathrm{p}} / a=1.602$ for the EBM; $R_{\mathrm{p}} / a=1.418$ and $R_{\mathrm{c}} / a=$ 1.218 for the ESM; $R_{\mathrm{p}} / a=1.540$ and $R_{\mathrm{c}} / a=1.492$ for the EPBM; and $R_{\mathrm{p}} / a=1.165, R_{\mathrm{s}} / a=1.295$, and $R_{\mathrm{c}} / a=1.122$ for the EPSDM. In addition, the dimensionless radial displacement $2 u_{0} G /\left[a\left(\sigma_{0}-\sigma_{R_{\mathrm{p}}}\right)\right]$ of the EPM, EBM, ESM, EPBM, and EPSDM is 1.357, 2.565, 2.010, 2.371, and 1.786, respectively.

Compared with the ESM and EPBM, the EPSDM represents the influence of the plastic bearing properties and
TABLE 2: Geometrical and mechanical parameters by Ogawa and Lo [2].

\begin{tabular}{lc}
\hline Parameters & Values \\
\hline Radius of the opening, $a(\mathrm{~m})$ & 1 \\
Initial stress, $\sigma_{0}(\mathrm{MPa})$ & 1 \\
Young's modulus, $E(\mathrm{MPa})$ & 5000 \\
Dilation angle, $\psi_{i}$ & 0 \\
Poisson's ratio, $v$ & 0.2 \\
Initial cohesion, $c(\mathrm{MPa})$ & 0.276 \\
Residual cohesion, $c_{\mathrm{r}}(\mathrm{MPa})$ & 0.055 \\
Internal friction angle, $\varphi\left(^{\circ}\right)$ & 35 \\
\hline
\end{tabular}

strain-softening characteristics on the surrounding rock state. In fact, most of the fractured and jointed rocks are prone to strain-softening characteristics after perfectly plastic. Therefore, in the deep underground engineering, the design of support parameters by using this paper's EPSDM may be more reasonable. 


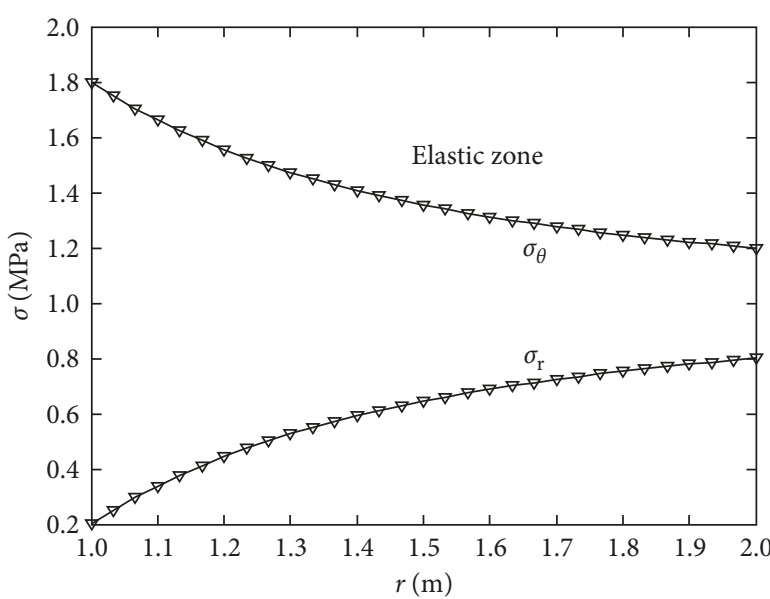

(a)

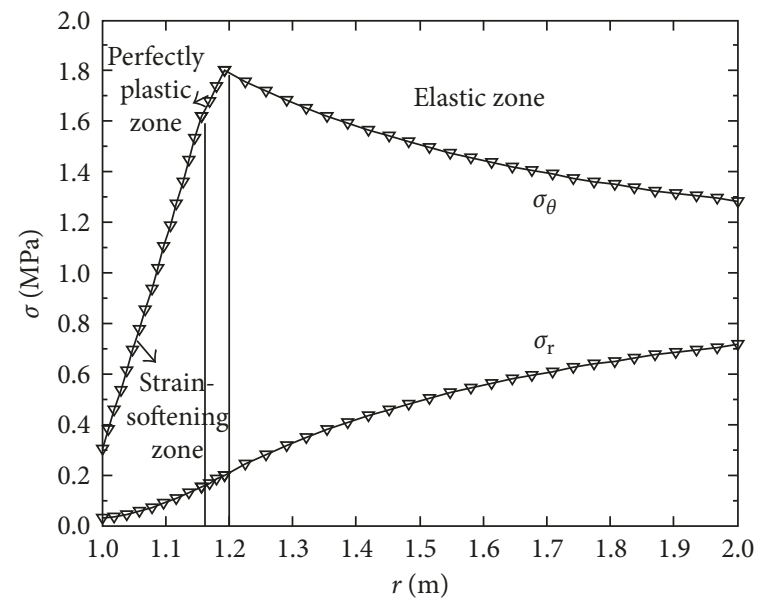

(c)

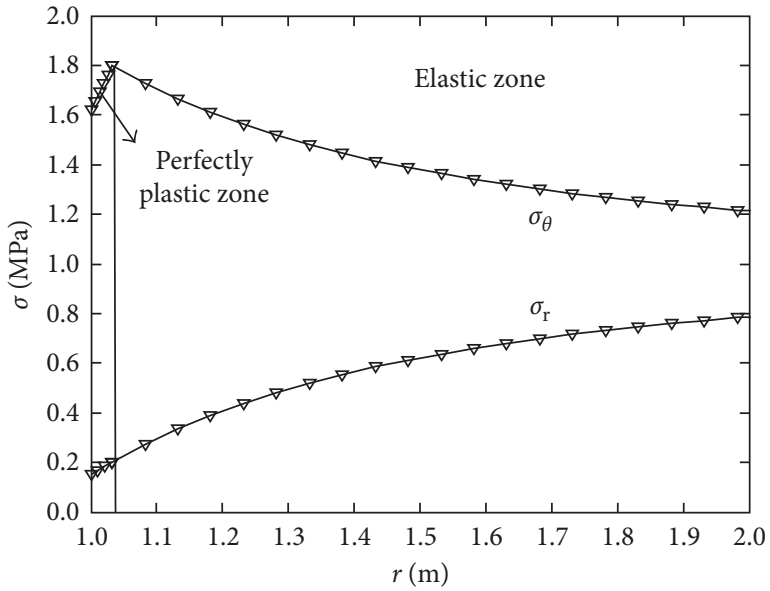

(b)

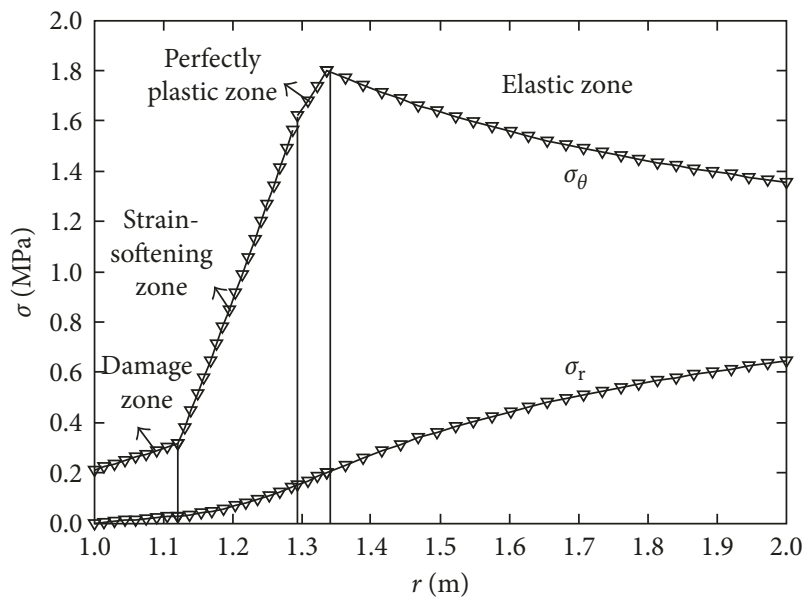

(d)

FIgURE 5: Stress distribution law of the EPSDM under different critical support resistance.

TABLE 3: Critical support resistance $\left(p_{\text {in }} / \sigma_{0}\right)$.

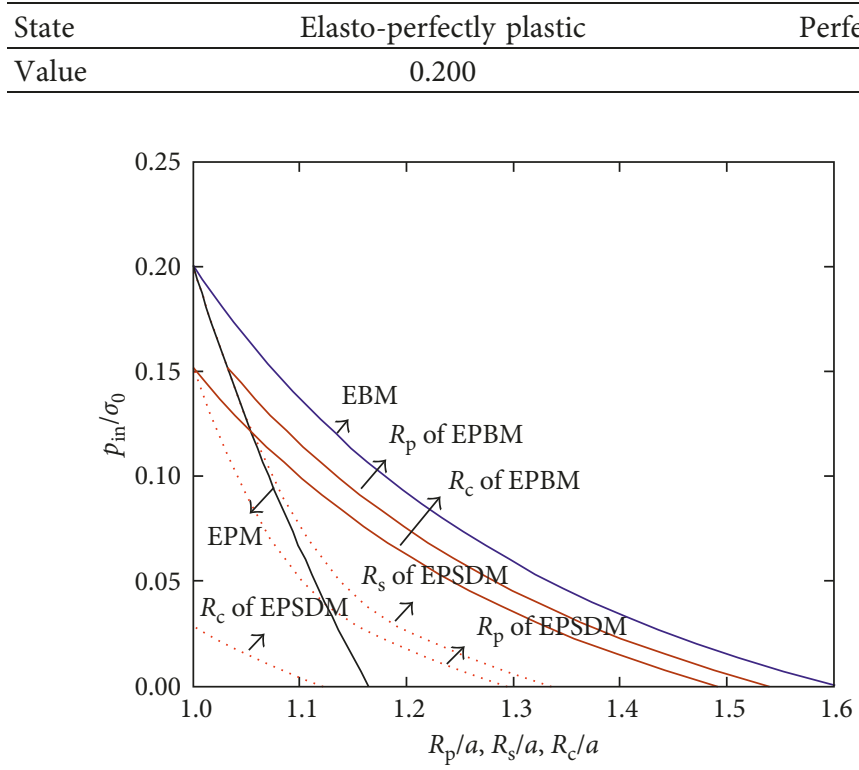

(a)

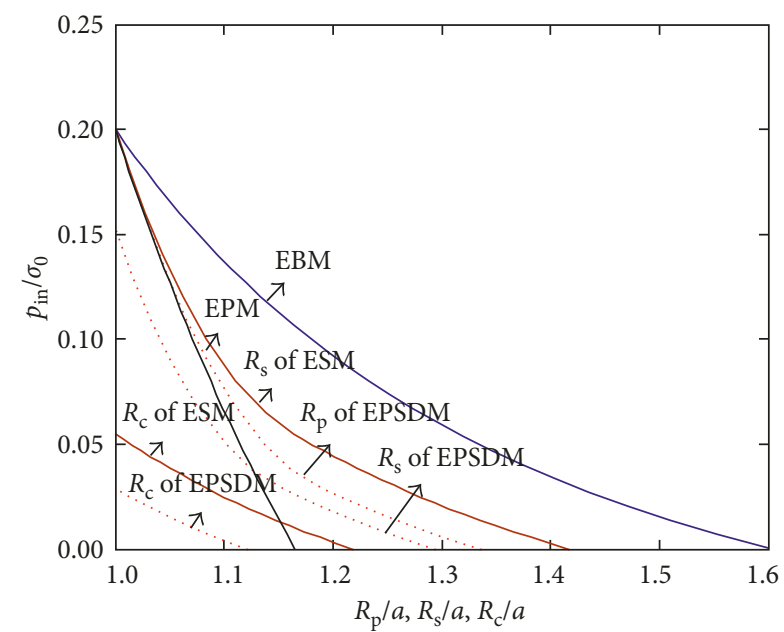

(b)

Figure 6: The influence of support resistance on the post-peak failure radii. 


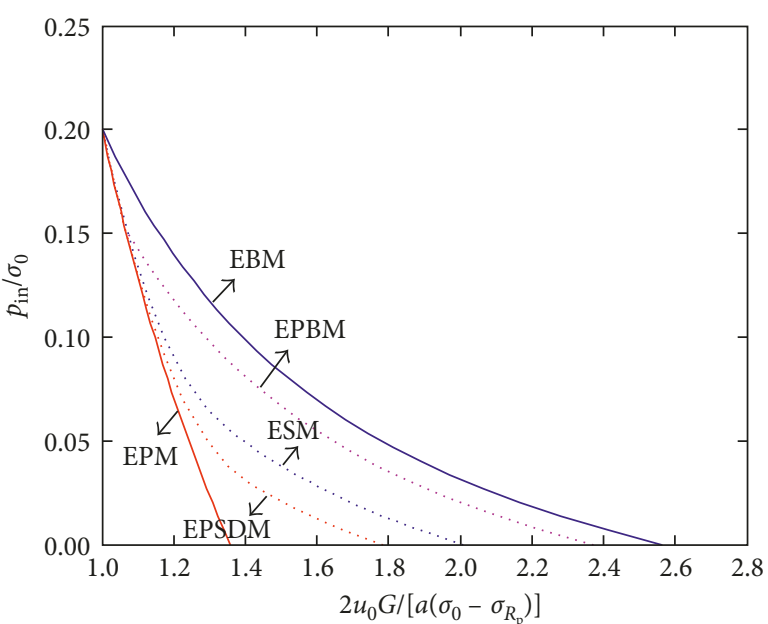

Figure 7: The influence of support resistance on the surface displacement.

TABLE 4: The post-peak failure radii and surface displacement when $p_{\text {in }}=0$.

\begin{tabular}{lccccc}
\hline Model & Transformation & $R_{\mathrm{p}} / a$ & $R_{\mathrm{s}} / a$ & $R_{\mathrm{c}} / a$ & $\begin{array}{c}2 u_{0} G / \\
{\left[a\left(\sigma_{0}-\sigma_{R_{\mathrm{p}}}\right)\right]}\end{array}$ \\
\hline EPM & $a=R_{\mathrm{c}}=R_{\mathrm{s}}<R_{\mathrm{p}}$ & 1.165 & 1.000 & 1.000 & 1.357 \\
EPSDM & $a<R_{\mathrm{c}}<R_{\mathrm{s}}<R_{\mathrm{p}}$ & 1.336 & 1.295 & 1.122 & 1.786 \\
ESM & $a<R_{\mathrm{c}}<R_{\mathrm{s}}=R_{\mathrm{p}}$ & 1.418 & 1.418 & 1.218 & 2.010 \\
EPBM & $a<R_{\mathrm{c}}=R_{\mathrm{s}}<R_{\mathrm{p}}$ & 1.540 & 1.492 & 1.492 & 2.371 \\
EBM & $a<R_{\mathrm{c}}=R_{\mathrm{s}}=R_{\mathrm{p}}$ & 1.602 & 1.602 & 1.602 & 2.565 \\
\hline
\end{tabular}

5.2. Case II: Parameter Analysis of EPSDM. A case of tunnel excavation in coal mine was used to study the influence of rock mass parameters on the post-peak failure radii and surface displacement. The typical rock mass parameters of the haulage roadway by Tang Kou coal mine in China were utilized. The haulage roadway is buried at about $1028 \mathrm{~m}$ underground, and the vertical stress and horizontal stress are 23.77 MPa and 23.04 MPa, respectively. Therefore, the in situ stress $\sigma_{0}$ is $23.4 \mathrm{MPa}$. The excavation radius $a$ is $3.0 \mathrm{~m}$, Young's modulus $E$ is $30.0 \mathrm{MPa}$, Poisson's ratio $v$ is 0.25 , strain-softening coefficient $\beta$ is 1.25 , initial internal friction angle $\varphi$ is $30^{\circ}$, and initial cohesion $c$ and residual cohesion $c_{R}$ are $5.85 \mathrm{MPa}$ and $2.0 \mathrm{MPa}$, respectively. The plastic shear strain increment $\Delta \gamma^{*}$ is 0.0001 . In addition, the yield parameter $b$ is zero, and the initial dilation angle are all $\psi_{\mathrm{p}}=\psi_{\mathrm{s}}=\psi_{\mathrm{c}}=15^{\circ}$.

5.2.1. The Influence of Residual Cohesion. Figures 8 and 9 indicate the effect of residual cohesion on the post-peak failure radii and surface displacement. With the continuous increase of the residual cohesion, the post-peak failure radii and surface displacement depict a nonlinear decrease characteristic. For instance, when $c_{\mathrm{r}}$ transforms from 1.0 MPa to $1.6 \mathrm{MPa}$, the dimensionless radii $R_{\mathrm{p}} / a, R_{\mathrm{s}} / a$, and $R_{\mathrm{c}} / a$ decrease by $0.222,0.217$, and 0.159 , with reduction of $11.78 \%, 11.74 \%$, and $10.25 \%$, respectively; the surface displacement decreases by $1.1 \mathrm{~mm}$, with reduction of $28.21 \%$.

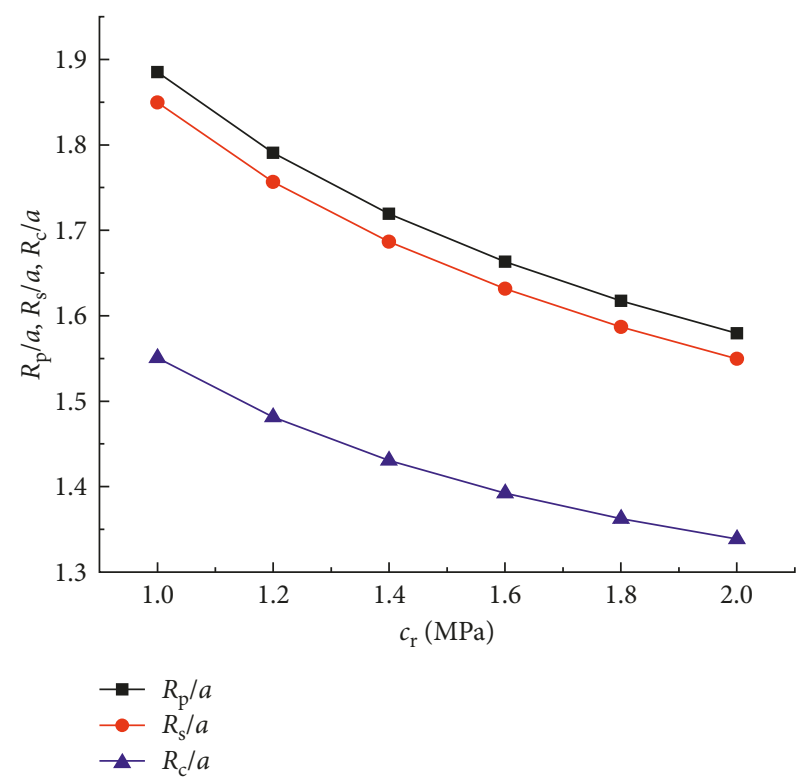

Figure 8: The values of $R_{\mathrm{p}}, R_{\mathrm{s}}$, and $R_{\mathrm{c}}$ under different $c_{\mathrm{r}}$.

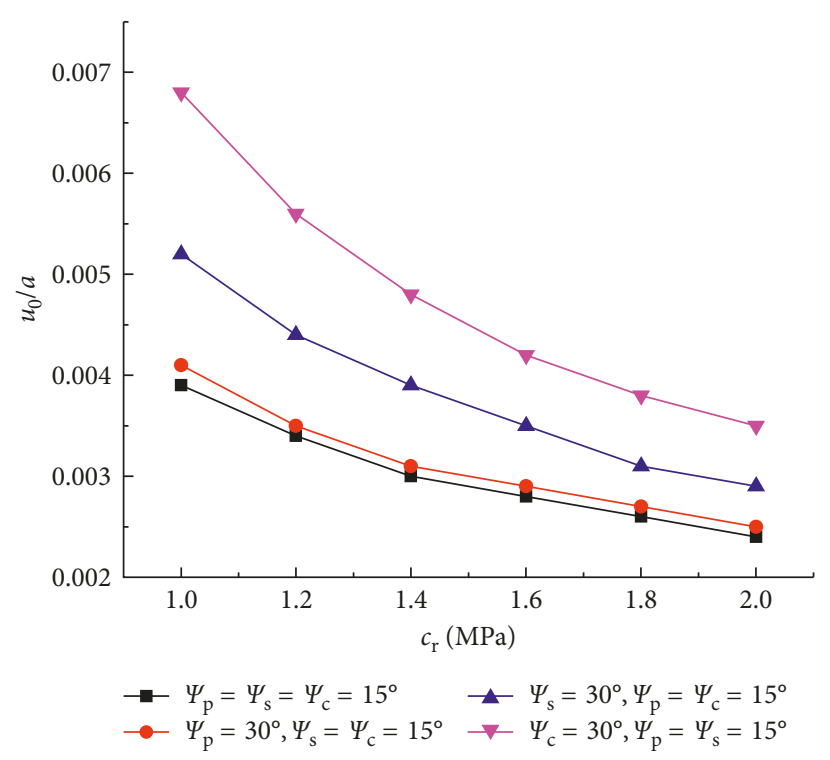

Figure 9: The values of $u_{0}$ under different $c_{\mathrm{r}}$ and $\psi_{i}$.

The above data show that the residual cohesion has an important influence on the surrounding rock state, especially for the extremely broken rock mass.

In addition, as shown in Figure 9, it can be seen that the surface displacement gradually increases with the increase of the dilatancy angle. This is mainly because the larger the dilatancy angle is, the higher the dilatancy coefficient is and the greater the volume expansion of surrounding rock is. Meanwhile, the influence of the dilatancy angle in the damage zone on the surface displacement is the most significant, whereas the dilatancy angle in the perfectly plastic zone has the lowest influence. 


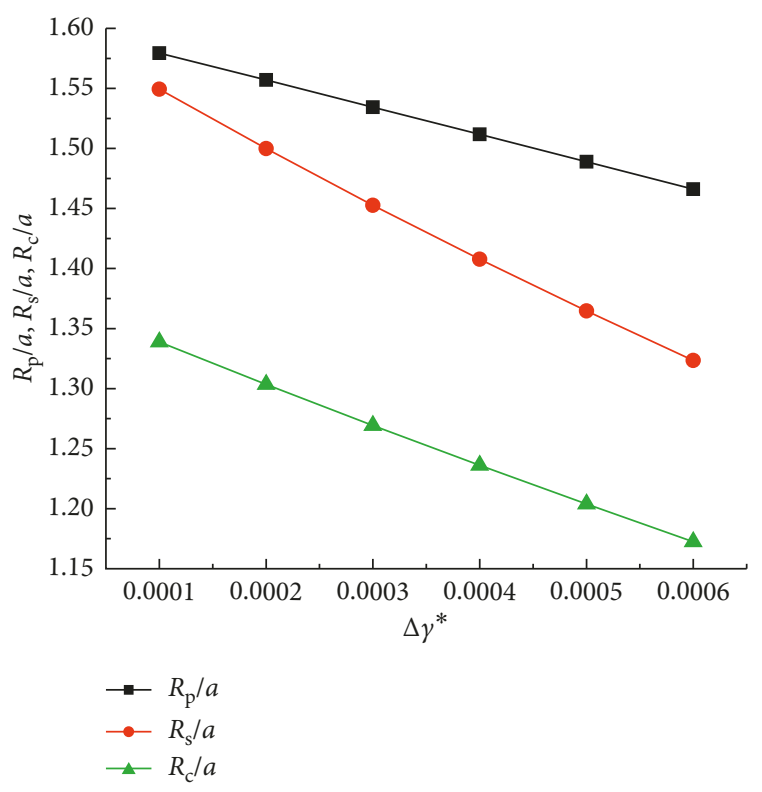

Figure 10: The values of $R_{\mathrm{p}}, R_{\mathrm{s}}$, and $R_{\mathrm{c}}$ under different $\Delta \gamma^{*}$.

5.2.2. The Influence of Plastic Shear Strain Increment. The effect of plastic shear strain increment on the post-peak failure radii and surface displacement is presented in Figures 10 and 11 , respectively. As $\Delta \gamma^{*}$ gradually increases, the dimensionless radii $R_{\mathrm{p}} / a, R_{\mathrm{s}} / a$, and $R_{\mathrm{c}} / a$ and the displacement $u_{0} / a$ all present the approximate linear decrease characteristics. Compared with $R_{\mathrm{p}} / a$ and $R_{\mathrm{c}} / a$, the reduction rate of $R_{\mathrm{s}} / a$ is the largest. For example, when $\Delta \gamma^{*}$ increases from 0.0001 to $0.0005, R_{\mathrm{p}} / a, R_{\mathrm{s}} / a$, and $R_{\mathrm{c}} / a$ are, respectively, reduced to $5.72 \%, 11.92 \%$, and $10.08 \% ; u_{0} / a$ is reduced to $16.67 \%$. The above data show that $\Delta \gamma^{*}$ has a crucial influence on the post-peak failure radii and surface displacement. The plastic bearing capacity of rock mass gradually increases with the increasing $\Delta \gamma^{*}$. As a result, the supporting resistance to maintain the stability of surrounding rock gradually decreases.

\subsubsection{The Influence of Strain-Softening Coefficient. Figures} 12 and 13 indicate the effect of strain-softening coefficient on the post-peak failure radii and surface displacement, respectively. It can be seen that the change of $\beta$ exerts important effects on $R_{\mathrm{p}}, R_{\mathrm{s}}, R_{\mathrm{c}}$, and $u_{0}$. As $\beta$ increases, the dimensionless radii $R_{\mathrm{p}} / a, R_{\mathrm{s}} / a$, and $R_{\mathrm{c}} / a$ and the displacement $u_{0} / a$ all increase. For instance, $\beta$ increases from $2 / 3$ to 2 and $R_{\mathrm{p}} / a, R_{\mathrm{s}} / a, R_{\mathrm{c}} / a$, and $u_{0} / a$ increase by 0.133 , $0.130,0.300$, and 0.0005 , respectively. Nevertheless, $\beta$ increases from 2 to $10 / 3$ and $R_{\mathrm{p}} / a, R_{\mathrm{s}} / a, R_{\mathrm{c}} / a$, and $u_{0} / a$ only increase by $0.026,0.026,0.077$, and 0.0002 , respectively. The above data also show that the strain-softening coefficient has the most significant influence on the damage zone radii.

5.2.4. The Influence of the Yield Parameter $b$. The influences of the yield parameter $b$ on the post-peak failure radii and surface displacement are displayed in Table 5. It can be seen that the change of the parameter $b$ exerts important effects

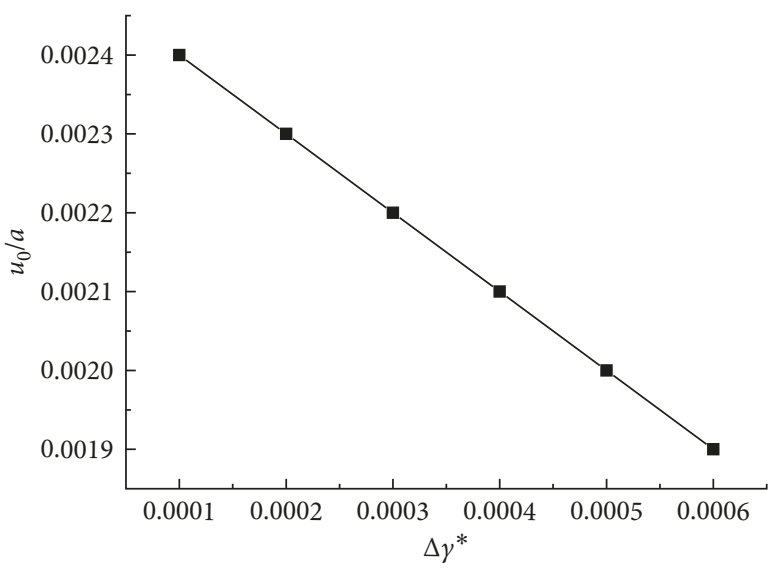

Figure 11: The values of $u_{0}$ under different $\Delta \gamma^{*}$.

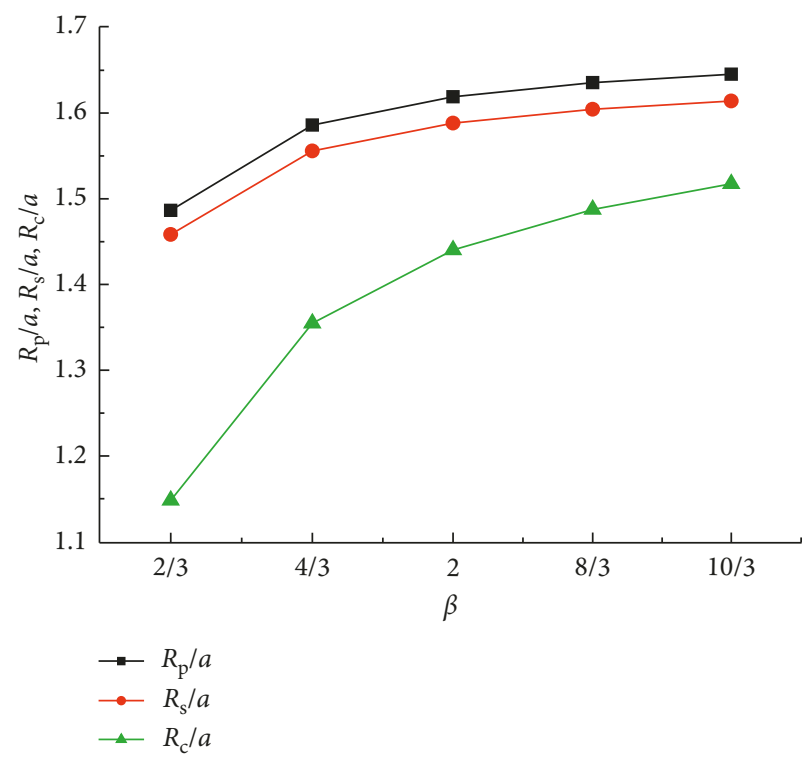

Figure 12: The values of $R_{\mathrm{p}}, R_{\mathrm{s}}$, and $R_{\mathrm{c}}$ under different $\beta$.

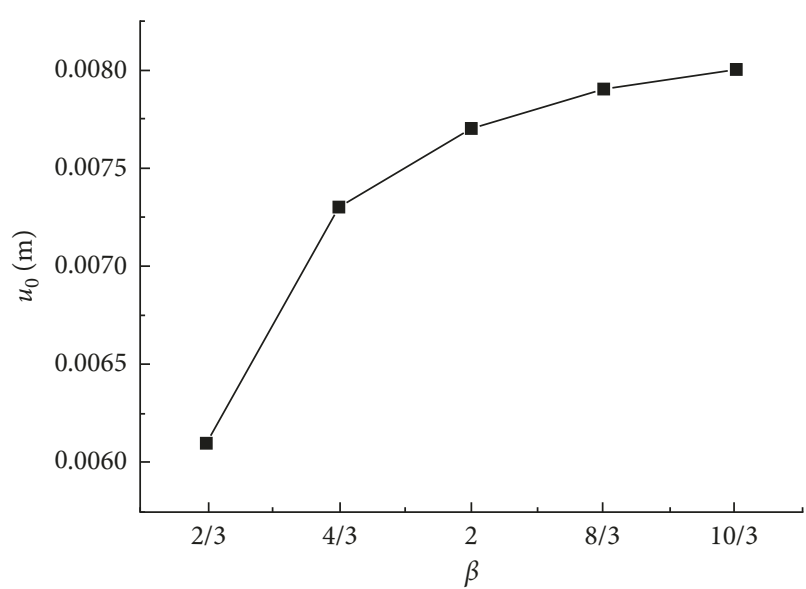

Figure 13: The values of $u_{0}$ under different $\beta$.

on $R_{\mathrm{p}}, R_{\mathrm{s}}, R_{\mathrm{c}}$, and $u_{0}$. As $b$ increases, the dimensionless radii $R_{\mathrm{p}} / a, R_{\mathrm{s}} / a$, and $R_{\mathrm{c}} / a$ and the displacement $u_{0} / a$ all decrease. For instance, $b$ increases from 0.2 to 0.8 and $R_{\mathrm{p}} / a$, 
TABLE 5: The influence of the parameter $b$ on the post-peak failure radii and surface displacement.

\begin{tabular}{ccccc}
\hline$b$ & $R_{\mathrm{p}} / a$ & $R_{\mathrm{s}} / a$ & $R_{\mathrm{c}} / a$ & $u_{0} / a(\%)$ \\
\hline 0.0 & 1.579 & 1.549 & 1.339 & 0.24 \\
0.2 & 1.448 & 1.422 & 1.226 & 0.20 \\
0.4 & 1.358 & 1.336 & 1.150 & 0.18 \\
0.6 & 1.293 & 1.273 & 1.094 & 0.16 \\
0.8 & 1.243 & 1.225 & 1.051 & 0.15 \\
1.0 & 1.203 & 1.186 & 1.017 & 0.14 \\
\hline
\end{tabular}

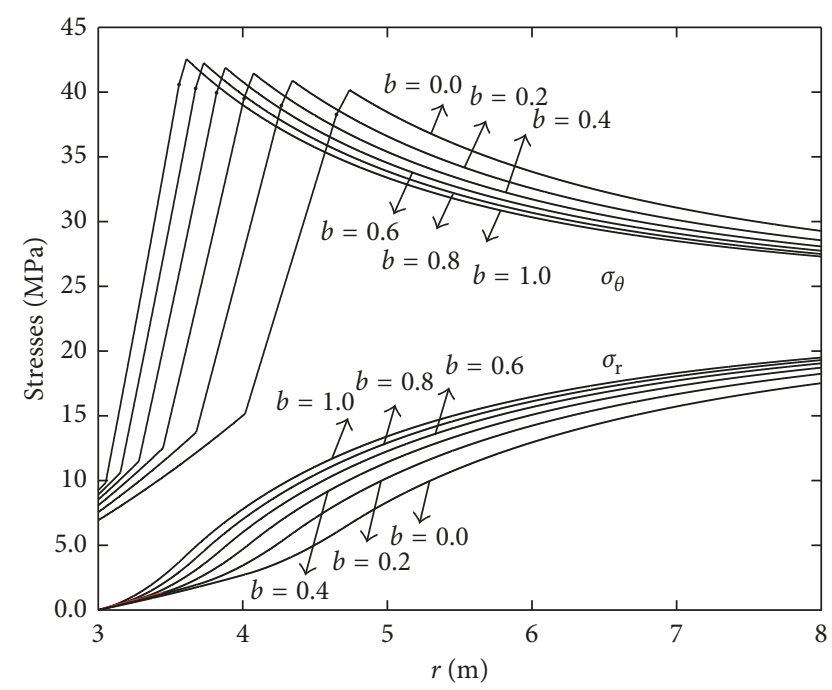

Figure 14: The influence of the parameter $b$ on the stresses of surrounding rock.

$R_{\mathrm{s}} / a, R_{\mathrm{c}} / a$, and $u_{0} / a$, respectively, decrease by $0.205,0.197$, 0.175 , and 0.0005. Moreover, as shown in Figure 14, it is indicated that the parameter $b$ has important influences on the stress distribution of surrounding rock as well. As parameter $b$ gradually decreases, the maximum circumferential stress $\sigma_{\theta}$ gradually keeps a decreasing change and transfers to the deep rock mass. Therefore, the design of the support scheme should take into account the parameter $b$.

\section{Conclusion}

Taking into account the plastic bearing capacity of strainsoftening rock mass, a new four-stage constitutive model was proposed. Meanwhile, a plastic shear strain increment was introduced to determine the critical condition where the strain-softening zone begins to develop. Then, based on the unified strength theory and four-stage constitutive model, a new closed-form solution of the circular opening was proposed. Compared with the numerical simulation results, the validity of the solution has been verified and several conclusions could therefore be drawn:

(1) As the supporting resistance is fully released, both the post-peak failure radii and surface displacement could be summarized as EBM $>E P B M>E S M>$ EPSDM $>$ EPM. Meanwhile, once the plastic shear strain increment is zero, the calculated results of the
EPSDM could be converted to the ESM's solution. Similarly, when strain-softening coefficient was zero or was large enough, the EPSDM turned to the EPM and EPBM, respectively. As the plastic shear strain increment was zero and the strain-softening coefficient was large enough, the calculated results of the EPSDM was found to be in accordance with the closed-form solution of the EBM.

(2) Compared with the above four models, the EPSDM reflects all the features of them, which represent the influence of the plastic bearing properties and strainsoftening coefficient on the surrounding rock state. Therefore, the design of support parameters by using the EPSDM may be more reasonable for the perfectly plastic strain-softening rock mass.

(3) The residual cohesion, plastic shear strain increment, and yield parameter $b$ are negatively correlated with the post-peak failure radii and surface displacement; however, the dilatancy angle and strain-softening coefficient are positively correlated. On the other hand, it was also clear that the dilatancy angle in the damage zone had the highest influence on the surface displacement, whereas the dilatancy angle in the perfectly plastic zone had the lowest influence. The strain-softening coefficient had the most significant influence on the damage zone radii. In conclusion, the research can provide an important theoretical basis for the design and stability analysis of the circular tunnel excavated in the perfectly plastic strain-softening rock mass.

\section{Conflicts of Interest}

The authors declare that there are no conflicts of interest regarding the publication of this paper.

\section{Acknowledgments}

The authors acknowledge the financial support by the State Key Development Program for Basic Research of China (2013CB227900).

\section{References}

[1] E. Detournay, "Elastoplastic model of a deep tunnel for a rock with variable dilatancy," Rock Mechanics and Rock Engineering, vol. 19, no. 2, pp. 99-108, 1986.

[2] T. Ogawa and K. Y. Lo, "Effects of dilatancy and yield criteria on displacement around tunnels," Canadian Geotechnical Journal, vol. 24, no. 1, pp. 100-113, 1987.

[3] H. S. Yu, Cavity Expansion Methods in Geomechanics, Kluwer Academic Publishers, Dordrecht, Netherlands, 2000.

[4] S. K. Sharan, "Analytical solutions for stresses and displacements around a circular opening in a generalized HoekBrown rock," International Journal of Rock Mechanics and Mining Sciences, vol. 45, no. 1, pp. 78-85, 2008.

[5] C. Carranza-Torres and C. Fairhurst, "Application of convergence-confinement method of tunnel design to rock masses that satisfy the Hoek-Brown failure," Tunnelling and 
Underground Space Technology, vol. 15, no. 2, pp. 187-213, 2000.

[6] C. Carranza-Torres, "Elasto-plastic solution of tunnel problem using the generalized form of the Hoek-Brown failure criterion," International Journal of Rock Mechanics and Mining Sciences, vol. 41, no. 3, pp. 480-481, 2004.

[7] S. K. Sharan, "Exact and approximate solutions for displacements around circular openings in elastic-brittle-plastic Hoek-Brown rock," International Journal of Rock Mechanics and Mining Sciences, vol. 42, no. 4, pp. 542-549, 2005.

[8] K. H. Park and Y. J. Kim, "Analytical solution for a circular opening in an elastic-brittle-plastic rock," International Journal of Rock Mechanics and Mining Sciences, vol. 43, no. 4, pp. 616-622, 2006.

[9] R. Chen and F. Tonon, "Closed-form solutions for a circular tunnel in elastic-brittle-plastic ground with the original and generalized Hoek-Brown failure criteria," Rock Mechanics and Rock Engineering, vol. 44, no. 2, pp. 169-178, 2011.

[10] Q. Zhang, B. S. Jiang, X. S. Wu, H. Q. Zhang, and L. J. Han, "Elasto-plastic coupling analysis of circular openings in elasto-brittle-plastic rock mass," Theoretical and Applied Fracture Mechanics, vol. 60, no. 1, pp. 60-67, 2012.

[11] Q. Zhang, B. S. Jiang, and H. J. Lv, "Analytical solution for a circular opening in a rock mass obeying a three-stage stressstrain curve," International Journal of Rock Mechanics and Mining Sciences, vol. 86, pp. 16-22, 2016.

[12] K. Mogi, "Effect of intermediate principal stress on rock failure," Journal of Geophysical Research, vol. 72, no. 20, pp. 5117-5131, 1967.

[13] D. J. Xu and N. G. Geng, "The variation law of rock strength with intermediate principal stress," Acta Mechanica Solida Sinica, vol. 6, no. 1, pp. 72-80, 1985, in Chinese.

[14] B. C. Haimson and C. Chang, "A true triaxial cell for testing mechanical properties of rock, and its use to determine rock strength and deformability of Westerly granite," International Journal of Rock Mechanics and Mining Sciences, vol. 37, no. 12, pp. 285-296, 2000.

[15] S. Q. Xu and M. H. Yu, "The effect of intermediate principal stress on the ground response of circular openings in rock mass," Rock Mechanics and Rock Engineering, vol. 39, no. 2, pp. 169-181, 2006.

[16] M. Q. You, "True-triaxial strength criteria for rock," International Journal of Rock Mechanics and Mining Sciences, vol. 46, no. 1, pp. 115-127, 2009.

[17] M. H. Yu, S. Y. Yang, S. C. Fan, and G. W. Ma, "Unified elastoplastic associated and non-associated constitutive model and its engineering applications," Computers \& Structures, vol. 71, no. 6, pp. 627-636, 1999.

[18] M. H. Yu, "Advance in strength theory of materials under the complex stress state in the 20th century," Applied Mechanics Reviews, vol. 55, no. 3, pp. 169-218, 2002.

[19] M. H. Yu, Unified Strength Theory and Its Applications, Springer \&Verlag, Berlin, Germany, 2004.

[20] J. C. Li, G. W. Ma, and M. H. Yu, "Penetration analysis for geo-material based on unified strength criterion," International Journal of Impact Engineering, vol. 35, no. 10, pp. 1154-1163, 2008.

[21] C. G. Zhang, J. F. Wang, and J. H. Zhao, "Unified solutions for stresses and displacements around circular tunnels using the unified strength theory," Science China Technological Sciences, vol. 53, no. 6, pp. 1694-1699, 2010.

[22] C. G. Zhang, J. H. Zhao, Q. H. Zhang, and X. D. Hu, "A new closed-form solution for circular openings modeled by the unified strength theory and radius-dependent Young's modulus," Computers and Geotechnics, vol. 42, pp. 118-128, 2012.

[23] X. M. Pan, J. Kong, Z. Yang, and C. Liu, "Secondary development and application of unifield elastoplastic constitutive model to ABAQUS," Rock and Soil Mechanics, vol. 31, no. 4, pp. 1092-1098, 2010, in Chinese.

[24] M. H. Yu, "Unified strength theory for geomaterials and its application," Chinese Journal of Geotechnical Engineering, vol. 16, no. 2, pp. 1-10, 1994, in Chinese.

[25] Y. K. Lee and S. Pietruszczak, "A new numerical procedure for elasto-plastic analysis of a circular opening excavated in a strain-softening rock mass," Tunnelling and Underground Space Technology, vol. 23, pp. 588-599, 2008.

[26] K. H. Park, B. Tontavanich, and J. G. Lee, “A simple procedure for ground response curve of circular tunnel in elastic-strain softening rock masses," Tunnelling and Underground Space Technology, vol. 23, no. 2, pp. 151-159, 2008.

[27] S. L. Wang, X. T. Yin, H. Tang, and X. Ge, "A new approach for analyzing circular tunnel in strain-softening rock masses," International Journal of Rock Mechanics and Mining Sciences, vol. 47, no. 1, pp. 170-178, 2010.

[28] Y. Li, S. Cao, N. Fantuzzi, and Y. Liu, "Elastoplastic analysis of a circular borehole in elastic-strain softening coal seams," International Journal of Rock Mechanics and Mining Sciences, vol. 80, pp. 316-324, 2015.

[29] Z. Guan, Y. Jiang, and Y. Tanabasi, "Ground reaction analyses in conventional tunneling excavation," Tunnelling and Underground Space Technology, vol. 22, pp. 230-237, 2007.

[30] J. X. Han, S. C. Li, S. C. Li, and W. M. Yang, "A procedure of strain-softening model for elasto-plastic analysis of a circular opening considering elasto-plastic coupling," Tunnelling and Underground Space Technology, vol. 37, pp. 128-134, 2013.

[31] E. Hoek and E. T. Brown, "Practical estimates of rock mass strength," International Journal of Rock Mechanics and Mining Sciences, vol. 34, no. 8, pp. 1165-1186, 1997.

[32] J. J. Wei, B. S. Jiang, and Q. Zhang, "Elastic-plastic-brittle unified solution of surrounding rocks in deep openings," in Proceedings of the International Symposium on Mine Safety Science and Engineering, vol. 26, pp. 1225-1233, Beijing, China, October 2011.

[33] B. S. Jiang, Q. Zhang, Y. N. He et al., "Elasto-plastic analysis of cracked surrounding rocks in deep circular openings," Chinese Journal of Rock Mechanics and Engineering, vol. 26, no. 5, pp. 982-986, 2007, in Chinese. 


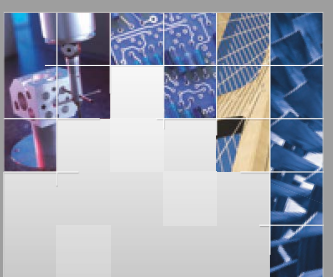

\section{Enfincering}
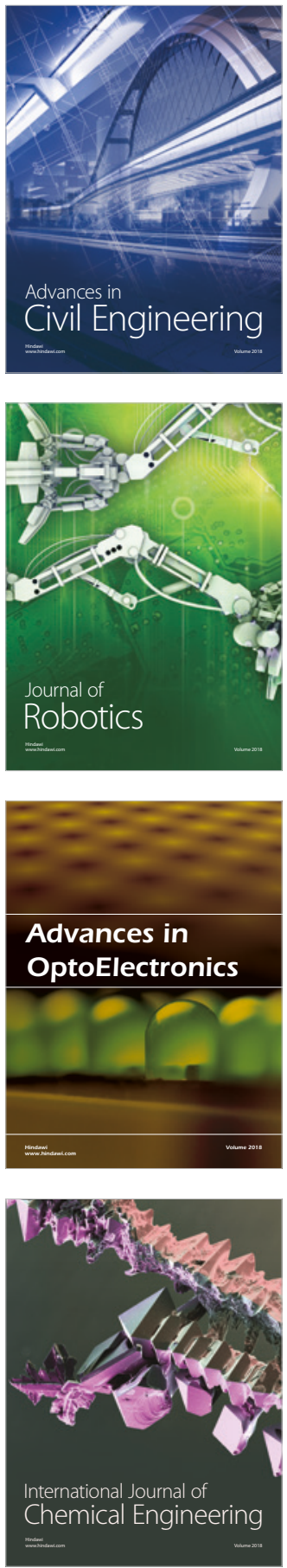

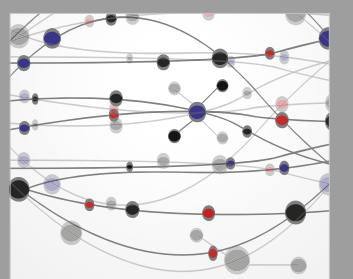

\section{Rotating \\ Machinery}

The Scientific World Journal

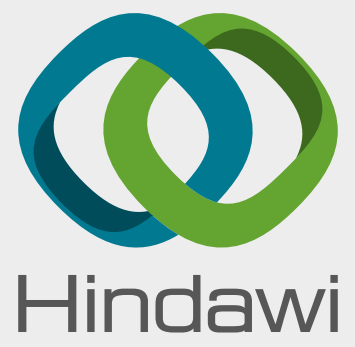

Submit your manuscripts at

www.hindawi.com
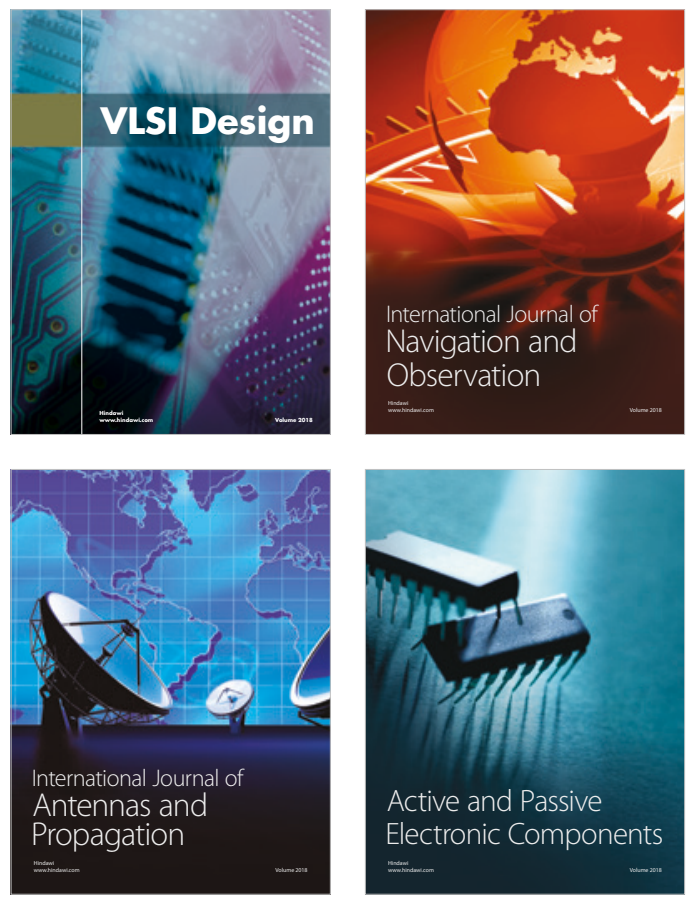
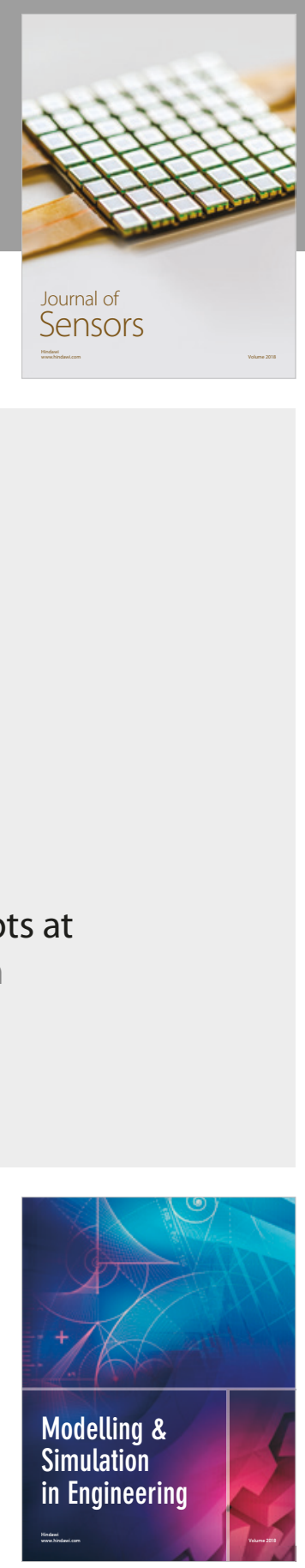

\section{Advances \\ Multimedia}
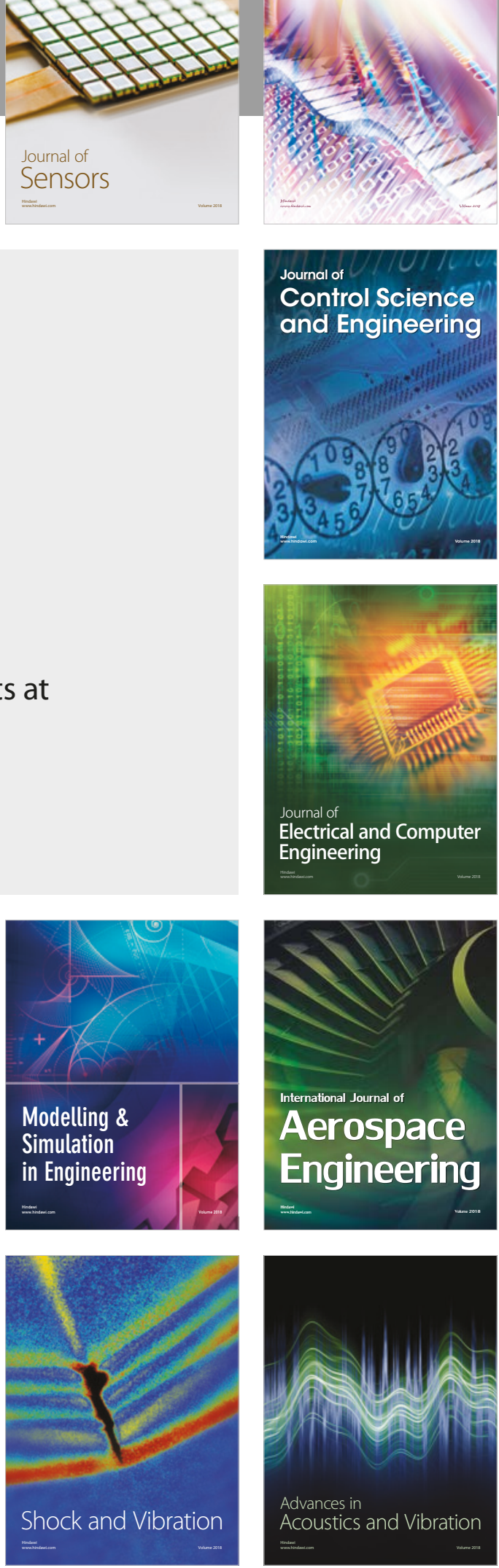